\title{
Reviewing Procedure vs. Judging Substance: How Increasing Bureaucratic Oversight Can Reduce Bureaucratic Accountability*
}

\author{
Ian R. Turner ${ }^{\dagger}$ \\ August 2021 \\ Forthcoming \\ Journal of Political Institutions and Political Economy \\ Volume 2, Issue 4, 2021.
}

\begin{abstract}
How does the scope of review affect bureaucratic policymaking? To explore this question, I consider a policymaking environment in which an expert agency develops policy that is upheld or overturned by an overseer who may have different policy goals. The agency can affect the quality of implementation through effort investments in addition to choosing the substantive content of policy. Under procedural review the overseer only reviews the agency's effort, which allows the agency to fully utilize its expertise. Substantive review also tasks the overseer with judging agencies' substantive policy choices, which can lead the agency to disregard its superior information and obfuscate to avoid reversal. Depending on the policy environment, this dynamic can either benefit or harm the overseer. In some cases the overseer can be made better off by having less transparent review institutions; that is, institutions that direct the overseer to only review procedure and preclude judging substance.
\end{abstract}

Keywords: Bureaucracy; Accountability; Judicial review; Policymaking; Formal Theory

${ }^{*}$ I would like to thank the editor Jeff Jenkins and two anonymous reviewers for exceptionally insightful comments that improved this article immensely. I would also like to thank John Patty, Maggie Penn, Brian Rogers, Justin Fox, Randy Calvert, Keith Schnakenberg, Andrea Aldrich, Deborah Beim, Dan Carpenter, Jack Paine, Tiberiu Dragu, Sean Gailmard, Mike Ting, Ryan Hübert, Christina Kinane, Chuck Shipan, Jesse Crosson, Ken Lowande, Jen Selin, Rachel Potter, Sharece Thrower, and seminar audiences at the Political Economy and Public Law Conference at the University of Southern California, the University of Wisconsin, the University of Rochester, the University of California, Berkeley, and Harvard University for very helpful discussions, criticisms, and suggestions throughout the evolution of this project. This article was previously circulated under the title, "Reviewing Procedure vs. Judging Substance: The Scope of Review and Bureaucratic Policymaking”. Early work on this project was supported by NSF Grant DGE-1143954. Of course, all errors are solely my own.

$\dagger$ Assistant Professor, Department of Political Science, Institution for Social and Policy Studies, Center for the Study of American Politics, Leitner Program in International and Comparative Political Economy, Yale University, 115 Prospect Street, New Haven, CT 06520, USA; ian.turner@yale.edu. 
Policymaking authority is delegated to bureaucratic agencies to take advantage of their policyrelevant expertise. But delegation also raises enduring normative concerns. On one hand, political principals like the general public, the president, or Congress may benefit from superior bureaucratic expertise informing government policy. On the other hand, delegation may also allow unelected bureaucrats to exploit their expertise to pursue policies that run counter to the wishes of these principals. Concern with this 'political agency problem,' as it is commonly referred to, emerges any time the agent's preferences diverge from those of the political principal. ${ }^{1}$

These agency problems may be solved by extensive oversight where an agency's decisions are subject to review, and possible invalidation, by another political actor such as a court or other oversight institution (e.g., the Office of Information and Regulatory Affairs). The hope is that these review institutions hold agencies accountable and deter them from making policy choices that run counter to the overseer's preferences in order to avoid having their policies invalidated. However, agency expertise advantages may introduce difficulties in the overseer's ability to judge whether an agency's actions are beneficial or justified. This may then weaken how effective oversight institutions are at enforcing accountability. Due to myriad expertise and information advantages bureaucratic agencies are often able to pursue their own ends even when their decisions are subject to formal oversight (e.g., Patty and Turner 2021; Potter 2019).

Moreover, bureaucratic agencies do more than develop the substance of policy. They also develop programmatic capacity that helps guide the agency's on-the-ground workforce to implement policy effectively. ${ }^{2}$ This introduces another wrinkle to agency oversight: The overseer must worry not only about divergent substantive policy choices based on an agency's ability to exploit its informational advantage, they must also consider providing proper incentives for the agency to invest in high quality policy implementation (Turner 2017).

\footnotetext{
${ }^{1}$ Overviews of political agency, from different angles, are provided by Bendor, Glazer and Hammond (2001), Gailmard and Patty $(2013 a, b)$, and Miller (2005).

${ }^{2}$ This is related to incorporating aspects of 'street-level bureaucracy' (Lipsky 1980). More generally, Carpenter (2001) distinguishes an agency's analytic capacity, which allows it to adequately craft the substance of policy, and an agency's programmatic capacity, which allows the agency to apply or enforce policy effectively.
} 
The scope of review. While oversight is carried out within all three branches of the US federal government, nearly all bureaucratic actions are subject to judicial review in various forms. Authorizing legislation contains judicial review provisions that specify who can challenge agency actions, what actions are subject to review, and the scope of judicial review. ${ }^{3}$ These oversight provisions are also the focus, and product, of political processes in Congress while the legislation is being drafted (Shipan 1997). ${ }^{4}$ One major component of the role of judicial oversight is the scope of review. The scope of review dictates what actions and which type of review overseers are directed to engage. Two major types of oversight are procedural review and substantive review. How does the type of review shape incentives to invest in capacity to implement policy effectively and the willingness of the agency to utilize its superior policy-relevant information? Relatedly, do overseers benefit from one approach to oversight and, if so, under what circumstances?

Procedural review entails an overseer examining whether an agency has followed all relevant guidelines, invested in the capacity to administer policy effectively, and the like without direct focus on the content of the policy. This could represent an agency's investment in research that allows it to better understand the contingencies of the policy environment in terms of the translation of policy choices into on-the-ground outcomes, developing procedures to ensure that policies are applied equitably across constituent populations, or, more generally, investment in the capacity to enforce its policy choices without making costly errors. ${ }^{5}$

For example, FEMA's provision of emergency housing for evacuees following Hurricanes Katrina and Rita was challenged in federal court on the basis that the system developed to evaluate assistance applications was not satisfactory and led to too many (avoidable) erroneous decisions. ${ }^{6}$ No one involved questioned the actual standards to receive assistance, nor was FEMA's authority to make these decisions in question. However, the court ultimately ruled against FEMA because

\footnotetext{
${ }^{3}$ See McCann, Shipan and Wang (2021) for a comprehensive description of legislative judicial review provisions.

${ }^{4}$ For several case studies, across policy areas, suggesting that Congress anticipates the role of judicial review in the policymaking process see Light (1991); Melnick (1983, 1994).

${ }^{5}$ Previous work argues courts have recently moved more toward procedural review of administrative actions (Stephenson 2006). Moreover, there is some evidence to suggest that when the scope of review has been explicitly outlined by statute that the Supreme Court attempts to honor that statutory mandate (Verkuil 2002).

${ }^{6}$ See Association of Community Organizations For Reform Now (ACORN), et. al. v. Federal Emergency Management Agency (FEMA), 463 F. Supp. 2d 26 (D.D.C. 2006).
} 
the agency had not developed sufficient capacity to effectively allocate assistance without making costly errors, in this case leaving many citizens homeless. For the purposes of my argument, the key feature is that oversight was not focused on the content of the policy itself, but rather on how well the agency would be able to implement the policy on the ground.

Substantive review entails an overseer also judging the actual content of policy choices made by agencies. This generally relates to the idea that overseers such as courts can help to enforce bureaucratic policy choices that do not run counter to the wishes of the overseer herself or those of some political principal (e.g., Epstein and O'Halloran 1999). This dimension of review is directly connected to the agency problem highlighted above. If the overseer sits at an informational disadvantage relative to the agency, then judging the substance of agency choices is difficult unless the agency itself chooses to reveal some, or all, of its private information.

Questions of permissible search and seizure fit well within substantive review as it is conceptualized here. Both implementation capacity and the substantive content of this class of policies are salient to oversight. The content of policy might be thought of as what the 'correct' is to establish probable cause. A move to either more lax or more stringent standards may signal that policy needs to be recalibrated to adapt to environmental conditions. ${ }^{7}$ Yet, even holding substantive standards fixed, the development of clear, effective procedures is of equal importance in terms of realized policy outcomes. For any permissible standard if there was not sufficient investment in the procedural framework adopted to train and guide street-level police officers who make on-the-ground decisions about when the standards are satisfied, we might reasonably expect that the policy will be applied in highly variable ways, leading to overall worse, and often impermissible, policy outcomes. Thus, even when the substance of policy seems permissible it may be that ineffective implementation leads an overseer to step in.

Whatever the type of review, a major role of oversight institutions is to enforce accountability. Whether this is understood as incentivizing the agency to invest effort toward high quality policy implementation or to set policy more closely in accordance with the goals of the overseer, oversight

\footnotetext{
${ }^{7}$ Of course, these policies must be constitutional as well. But, if there is any level of discretion in setting these standards then the general connections I draw here follow.
} 
is thought to be effective in disciplining bureaucratic behavior by forcing agencies to operate in the shadow of review. In this paper, I develop an argument that ex post review institutions, such as judicial review, can harm accountability depending on the type of review utilized. ${ }^{8}$ Through the analysis of two variants of a formal model of policymaking I characterize different ways that procedural and substantive review can enhance, or harm, accountability on both effort and substantive dimensions. In the first variant, the procedural review model, the overseer only observes an ex ante effort investment made by the agency that improves the implementation precision of policy outcomes. ${ }^{9}$ In the second variant, the substantive review model, the overseer observes both the agency's effort investment and the substantive policy choice made by the agency, potentially learning about the policy environment through the agency's policy choice.

Procedural review allows the agency to fully utilize its policy-relevant information because it does not have to worry about the overseer judging the substance of its choices. The cost of this, from the overseer's perspective, is not learning anything about the agency's private information, which may be undesirable if the overseer and agency have different policy goals. In this way, purely procedural review reduces the overseer's influence on substantive policy choices. However, a potential upside is that when policy disagreement is not too large the agency's ability to utilize their expertise when setting the substance of policy may produce strong incentives to invest high effort toward implementation.

When the overseer is also able to judge the substance of agency policy the overseer may perfectly learn the agency's private information and provide strong 'ideological oversight.' However, this learning is based on the agency's own substantive policy choices. There are only limited circumstances, predicated on policy agreement between the actors, in which the agency will reveal this information through its actions. Otherwise, the agency will obfuscate with some of its substantive

\footnotetext{
${ }^{8}$ For related, but distinct, arguments about potential weaknesses of judicial review see Melnick (1983), Shapiro and Levy (1995), and Wagner (2012).

${ }^{9}$ Following the effort investment aspect of the model, the theory of policymaking developed here complements the literature on policy development and valence, which spans political and institutional contexts (e.g., Callander 2011; Callander and Martin 2017; Hirsch and Shotts 2015, 2018; McCarty 2017). In a sense, this article provides an applied microfoundation for policy valence in a bureaucratic setting, similar to how Hitt, Volden and Wiseman (2017) endogenize policy valence in the context of legislative policymaking.
} 
policy choices to avoid reversal by either foregoing policy change altogether, which occurs when policy disagreement is extreme, or only partially revealing its private information, which arises under moderate policy disagreement. The agency disregards its own superior information and either appeases the overseer by choosing less ambitious policy than it believes is required or exaggerates the extremity of policy intervention that is called for given the facts on the ground. This dynamic subverts the very rationale supporting delegation to expert agencies in the first place.

Moreover, when the overseer reviews the substance of agency policy high effort investments can increase the discretion the agency has to pursue policies in line with its information. In some cases this may lead to higher effort and policy choices that benefit an overseer that disagrees with the agency on policy. In other cases higher effort leads the agency to obfuscate in ways that harm overseer welfare by inducing the agency to choose policies that run counter to overseer preferences. It is precisely in those latter environments where we might see the overseer being harmed by the additional information afforded through substantive review. Indeed, I show that when the agency obfuscates by exaggerating the necessity for extreme policy intervention the overseer would be better off with less information while monitoring the agency. That is, I characterize environments in which, through upstream effects on agency policymaking incentives, more information in the review process harms the overseer's interests. In those cases, increasing bureaucratic oversight reduces bureaucratic accountability and purely procedural review would produce more desirable policymaking behavior from the overseer's perspective.

Accountability and oversight. Oversight comes in many forms. In terms of enforcing political accountability prevalent review mechanisms include elections, ${ }^{10}$ presidential vetoes, ${ }^{11}$ Congressional oversight, ${ }^{12}$ and judicial review. ${ }^{13}$ Much of the previous research demonstrates how oversight may lead to policymaking pathologies like pandering when policymakers have career or reputational

\footnotetext{
${ }^{10}$ Ashworth (2012) provides an overview of research on electoral accountability.

${ }^{11}$ For example, Cameron (2000), Groseclose and McCarty (2001).

${ }^{12}$ For example, Bawn (1995), Gailmard (2009), Lowande and Potter (2020).

${ }^{13}$ For example, Bueno de Mesquita and Stephenson (2007), Clark (2016), Fox and Stephenson (2015), Fox and Vanberg (2014), Patty and Turner (2021), Shipan (2000), Turner (2017, 2019).
} 
concerns. ${ }^{14}$ In all of these cases the desire by politicians to remain in office, avoid being fired or demoted, or avoid having their policies vetoed leads them to disregard their superior private information due to reputational considerations. Relatedly, scholars have also studied how institutions promoting transparency affect accountability. Many of these studies have highlighted how increasing the transparency of policymaking may harm accountability. ${ }^{15}$ Building on existing studies, I extend this line of inquiry by exploring how increasing the transparency of agency actions in the review process can impact accountability negatively through a novel channel: policy exaggeration.

Patty and Turner (2021) study ex post review in a similar environment and characterize when an agent will disregard policy-relevant information and "cry wolf," or propose policy changes that are more extreme than is called for by the policy environment. The authors' primary focus in that article is when the overseer would prefer to have her review powers completely set aside (nontransparency), thereby allowing the agency to enact policy entirely unencumbered by review, to avoid the introduction of this perverse incentive. While I also show that increasing the transparency of agency actions (in this case vis-à-vis the addition of substantive review) can lead the agency to obfuscate by exaggerating the level of policy change needed, I study a more nuanced environment in which both the substance of agency choices and effort investments impact the overall quality of policy. This allows the juxtaposition of purely procedural review and the addition of more transparency of agency decision-making introduced through substantive review. Thus, the institutional design questions in this paper are related to, but substantively distinct from, those motivating Patty and Turner (2021): In this article I show that the scope of review affects the bundle of agency incentives across these two important policymaking dimensions, and that sometimes it is better for overseers to only engage in procedural review, which is an environment with less transparency of agency decision-making. This analysis is not possible in Patty and Turner (2021) since that article only focuses on the ability of oversight to influence the spatial location of policy.

In other related work, Turner (2017) studies how purely procedural oversight impacts agency

\footnotetext{
${ }^{14}$ For an overview of these pathologies see Gersen and Stephenson (2014). Also see, for example, Canes-Wrone, Herron and Shotts (2001).

${ }^{15}$ For example, Fox (2007), Fox and Van Weelden (2012), Patty and Turner (2021), and Prat (2005).
} 
effort incentives even when there is no preference disagreement between the reviewer and agency. In contrast, I characterize how procedural review impacts agency effort incentives in the presence of preference disagreement and illustrate how both effort incentives and incentives to follow policyrelevant information are affected when review institutions vary. Thus, in this article the overseer has the opportunity, if engaged in substantive review, to potentially influence substantive policy in a direction she prefers but this can sometimes backfire and lead the agency to make choices that run counter to overseer interests precisely because of this increased control. Moreover, in some cases this substantive downside could be exacerbated by high effort, further highlighting the value of modeling both effort investments to ensure effective implementation and setting the substantive content of policy spatially.

This article incorporates aspects from these related studies and offers insights unique to the environment when both purely procedural and substantive review are considered in tandem. Ultimately, the results provide insight into the trade-offs between agency effort and expertise as well as between the two different styles of oversight. Further, these trade-offs provide implications for how oversight may, or may not, provide for bureaucratic accountability and how the scope of review might be designed to promote high quality policymaking across different political environments.

\section{The model}

I analyze a two-player, non-cooperative game between a bureaucratic agency, $A$, that makes policy and an overseer or reviewer, $R$, that has the power to review and invalidate agency policy actions. The agency is expert in the sense that it learns private policy-relevant information, and is directed by statute to make policy. The overseer is empowered to review and overturn (or, veto) agency-made policy and return policy to an exogenous status quo.

Sequence of play. The agency first invests high or low effort toward the quality of policy implementation, ${ }^{16}$ denoted by $e \in\{0,1\}$ where $e=0(e=1)$ is low (high) effort. High effort leads to a

\footnotetext{
${ }^{16}$ This can be thought of as an investment in agency capacity that allows for higher quality policy implementation (Huber and McCarty 2004; Ting 2011; Turner 2017). More generally, this is conceptually similar to models of policy valence (e.g., Hirsch and Shotts 2015), and what Carpenter (2001) refers to as programmatic capacity.
} 
net effort cost, $\kappa>0$. This captures how hard the agency works to develop relevant programmatic capacity to implement policy precisely. Formally, effort investment directly affects an implementation shock, denoted by $\varepsilon(e) \in \mathbb{R}$. The shock depends on the agency's effort choice and is distributed according to $F_{\varepsilon}(e)$ with mean zero and variance, $V_{\varepsilon}(e) \in(0,1) .{ }^{17}$ Mean zero implies that the shock is centered on the agency's substantive policy choice. The variance of $\varepsilon(e)$ when the agency invests high effort is less than under low effort, $V_{\varepsilon}(1)<V_{\varepsilon}(0)$. This ensures that high effort investment produces more precise policy outcomes than low effort investments.

Following the agency's effort investment, Nature reveals a true state of the world, $\omega \in \Omega=$ $\{0,1, \theta\}$ where $\theta>\underline{\theta}:=1+V_{\varepsilon}(0)-V_{\varepsilon}(1),{ }^{18}$ to the agency. The ex ante probability that the true state is $\omega$ is $p_{\omega} \in(0,1)$. The three different states represent whether the policy environment calls for little to no policy change $(\omega=0)$, moderate policy change $(\omega=1)$, or extreme policy change $(\omega=\theta)$. When $\underline{\theta}<\theta<2$ I refer to extreme policy change as low urgency and $\theta>2$ as high urgency, following terminology in Patty and Turner (2021). The value of $\omega$ represents the agency's sincere (expert) opinion about how much policy ought to be adjusted to match the facts on the ground. Upon observing $\omega$ the agency sets a substantive 'policy target,' denoted by $x_{A} \in X=\{0,1, \theta\}$. This substantive policy choice can be thought of as a target because realized, agency-made policy outcomes are conditional on $\varepsilon(e) .{ }^{19}$

Finally, following the agency's choices the overseer reviews the agency and chooses to either uphold or overturn the agency's policy, denoted by $r(\cdot) \in\{0,1\}$ where $r=0$ is uphold and $r=1$ is overturn. If the overseer upholds the agency then final policy consists of the agency's spatial policy choice and the effort-specific implementation shock $\varepsilon(e)$ and if the overseer overturns then final policy is spatially located at $x=0$ with an implementation shock drawn from $F_{\varepsilon}(0)$. Once the overseer's review decision is made $\varepsilon$ is realized and final policy is generated according to the

\footnotetext{
${ }^{17}$ Bounding the variances above by one is done to simply rule out implementation errors shifting outcomes all the way to another substantive policy choice.

${ }^{18}$ The lower bound $\underline{\theta}:=1+V_{\mathcal{\varepsilon}}(0)-V_{\mathcal{\varepsilon}}(1) \in(1,2)$ is simply to ensure the ordering of preference divergence thresholds in the substantive review model illustrated in Figure 1 (specifically, it ensures that $\beta_{\text {align }}^{S}(1)<\beta_{\text {ext }}(0)$ ).

${ }^{19}$ Huber and McCarty (2004) has a similar 'target/shock' set-up.
} 
following expression:

$$
y= \begin{cases}x_{A}+\varepsilon(e) & \text { if } R \text { upholds } \\ \varepsilon(0) & \text { if } R \text { reverses }\end{cases}
$$

If the agency is overturned then it internalizes a reversal cost, denoted by $\pi \in(0,1)$. This can represent a reputational cost, opportunity costs of time wasted on policy that will never be realized, or a direct cost such as fines, demotions, or having budgets reduced. If one understands $\pi$ as a reputational cost then it can also represent a measure of agency independence where $\pi$ is negatively correlated with independence. Agencies with low independence will have higher reputational costs and highly independent or insulated agencies may worry less about reputation and therefore have lower reversal costs.

Information and oversight. I analyze two variants of the model that differ only in the information available to the overseer at the time of review. In the procedural review model the overseer only observes the agency's effort before making her review decision. This choice is represented by $r(e) .{ }^{20}$ In the substantive review model the overseer observes both the agency's effort investment and substantive policy choice. This choice is represented by $r\left(x_{A}, e\right)$. In the former case the overseer is only asked to ensure that the agency has followed all relevant procedural requirements and developed sufficient capacity for quality implementation. In the latter case the overseer not only takes the agency's investments toward implementation into account, but is also directed to judge the substance of the agency's policy.

\footnotetext{
${ }^{20}$ Of course, in reality when review occurs the actual policy, not just procedural language, is publicly available. One should not take the model to imply that when overseers are directed to ignore substance that they literally cannot observe either that the agency took action or the action itself. Rather, this information structure captures realistic environments in which the content of policy is very clearly within the purview of the agency and therefore not under question, the overseer is a generalist (e.g., courts) assessing highly technical actions taken by bureaucratic agencies and therefore unable to adequately judge content, or simply environments in which overseers take seriously the scope of review they are asked to adhere to and therefore do not render judgments based on content (Verkuil 2002). The comparison of institutions at the heart of this article does not depend on one interpretation of the information structure since this set-up captures any of the aforementioned variants of oversight.
} 
Preferences and equilibrium. Players' interests are captured by the following payoff functions:

$$
\begin{aligned}
& u_{R}(e, x, r)=-(\omega-\beta-y)^{2}, \\
& u_{A}(e, x, r)=-(\omega-y)^{2}-\kappa e-\pi r,
\end{aligned}
$$

where the parameters are exogenous and common knowledge. The overseer is biased relative to the agency, which is captured by $\beta>0$. Specifically, her bias induces her to prefer policy that is less ambitious, or closer to the status quo, than the agency: $y=\omega-\beta$. In contrast the agency wants final policy to match the state: $y=\omega$. In addition, the agency is motivated to avoid reversal (i.e., avoid paying $\pi$ ). Both players value high effort implementation to reduce the potential impact of $\varepsilon(e)$ on final policy, but there is conflict between the players on this dimension since the agency is the only player that internalizes the cost of doing so.

The agency's effort and substantive policy strategies are $s_{A}^{e}$ and $x_{A}(\omega)$, respectively. The overseer's review strategy, $s_{R}(\cdot)$, varies based on the information available to her. $s_{R}(e)$ denotes the overseer's review strategy in the procedural review model where she only observes $e$ and $s_{R}\left(x_{A}, e\right)$ denotes the analogous strategy for the substantive review model. The overseer's beliefs are denoted by $b_{R}\left(x_{A}\right) \cdot{ }^{21}$ I analyze pure strategy perfect Bayesian equilibrium, which requires that the overseer hold correct beliefs updated via Bayes' rule on the path of play and that both players make choices to maximize their subjective expected payoffs given the strategies of other players.

Model discussion. It is worth taking a moment to connect effort investments to agency policymaking procedures conceptually. Procedural review largely focuses on ensuring agencies are making decisions that respect fairness criteria, due process, and overall equal application of law. Doing so involves the agency utilizing resources to design procedural frameworks that help to guide, for example, street-level bureaucrats to uniformly apply substantive policy standards or, more generally, investing in capacity through an expanded workforce, improved technology, or updated processes to aid in high quality policy administration. Examples include developing clear guidelines for in-

\footnotetext{
${ }^{21}$ These beliefs are only applicable in the substantive review model since the overseer never has an opportunity to update her beliefs regarding $\omega$ in the procedural review model.
} 
teracting with the public, an expanded workforce to conduct inspections to ensure workplace safety (Huber 2007), or improving logistical capacity to accurately assess applications for assistance. In all of these cases the effectiveness of realized policy outcomes depends crucially on the agency's ability to implement policies in line with the values noted above. This ability, in turn, is often either improved or harmed based on the level of effort (or, more generally, productive investment) the agency allocates toward these goals. Targeting these issues in the oversight process most often involves assessing the procedures and processes of enforcement developed by the agency and whether they are sufficient to ensure that errors will be minimized in the application of policy, which depends on the agency's investment in these processes. ${ }^{22}$ In this way, procedural choices affect the realized substantive impact of policy, the quality of which is impacted by the effort exerted, even while holding the substantive content of policy fixed. The variance described above captures this dynamic formally.

Allowing for different policy urgency based on the value of $\theta$ serves a technical purpose of breaking indifference between the obfuscating to appease and obfuscation through exaggeration strategies analyzed below, but more importantly it allows for interesting substantive comparisons of policy environments. As an example, consider national security policy for dealing with countries $A$ and $B$ where $\omega$ represents intelligence on the ground about security threats posed by each country. Further, suppose that country $A$ is (relatively) low urgency from the perspective of national security so that $\theta<2$ and country $B$ is (relatively) high urgency so that $\theta>2$. If $\omega=0$ then the agency learns there is no compelling reason to alter the government's approach to those countries based on security concerns. If instead $\omega=1$ then the agency learns that some moderate adjustment to policy should be initiated in order to account for a small increased threat to national security. Not doing so would be costly, perhaps temporarily leading to tense relations with the country in question, but not as costly as a failure to respond to an extreme threat, which might be all-out conflict.

Now suppose that $\omega=\theta$. In both cases when $\omega=\theta$ extreme policy change is called for

\footnotetext{
${ }^{22}$ A salient recent example involves state-level voter identification laws. Many of the court-mandated injunctions induced by adoption of these laws centered primarily on the determination that states had not adequately demonstrated that they would be able to enforce the laws fairly (or efficiently) given the procedures they had designed to do so (e.g., Applewhite, et. al. v. Commonwealth of Pennsylvania, et. al., 330 M.D. 2012).
} 
based on new intelligence and the downside of not doing so is large. But countries $A$ and $B$ vary in the threat they pose based on policy misalignment - in this case, not adjusting policy based on new information regarding country $A$ would lead to smaller losses than those from not adjusting to new security threats from the higher urgency threat posed by country $B$. In that sense, the policies chosen to approach relations with country $B$ are of greater concern than those for approaching relations with country $A$ because the downside risk for not adjusting policy appropriately, when extreme change is called for based on new intelligence, leads to larger substantive losses. Perhaps this reflects the expected intensity of possible conflict across the two countries. Any conflict is worse than temporarily soured relations, but the severity of conflict will vary depending on the country in question. This is captured formally by the magnitude of $\theta$. More generally, this means that environments in which agencies are either deterred from, or reversed following, implementing large policy changes will have different impacts depending on the urgency of the policy environment $\theta$.

\section{Reviewing procedure}

In the procedural review model the overseer only observes the agency's effort investment. This implies that in equilibrium the agency always matches substantive policy to the state: $x_{A}^{P}(\omega)=\omega$. Since the overseer cannot condition its review decision on $x_{A}$ and the substantive policy and effort are separable in the agency's payoff function, the agency is always better off minimizing spatial policy losses by setting substantive policy to match the state. Given that the agency is always able to target policy to match the state, the question in the procedural review model is under what conditions the agency will invest high effort to improve the quality of policy implementation.

The overseer chooses between upholding and overturning the agency based on its observation

of $e$ and correct beliefs regarding the agency's substantive policy strategy $x_{A}^{P}(\omega)$. If the overseer chooses to overturn the agency then final policy is set at $x=0$ with implementation shock $\varepsilon(0)$. Thus, the overseer's subjective expected payoff for overturning the agency is given by:

$$
-p_{0}\left(\beta^{2}\right)-p_{1}\left((1-\beta)^{2}\right)-p_{\theta}\left((\theta-\beta)^{2}\right)-V_{\varepsilon}(0)
$$


Since there is no policy change the overseer knows that she will lose $(\omega-\beta)^{2}$ for each $\omega$, which is weighted by the probability that a given $\omega$ is realized. In addition, the overseer knows that she will have to also internalize low effort imprecision of policy based on the policy shock following agency reversal $\left(V_{\varepsilon}(0)\right)$.

Alternatively, the overseer could uphold the agency. In this case her subjective expected payoff is given by:

$$
-\beta^{2}-V_{\varepsilon}(e)
$$

The overseer knows that the agency will match substantive policy to the state. That means in terms of substantive policy choices the overseer only loses utility based on her bias $\beta$ since she would have preferred policy be closer to the status quo. The overseer also loses utility based on the implementation imprecision associated with agency-made policy, $V_{\varepsilon}(e)$. She loses less utility when the agency invested high effort due to lower expected implementation errors (i.e., $V_{\varepsilon}(1)<V_{\varepsilon}(0)$ ). Combining and rearranging these subjective expected payoffs yields the following optimal review strategy:

$$
s_{R}^{*}(e)= \begin{cases}\text { Uphold: } r=0 & \text { if } V_{\varepsilon}(0)-V_{\varepsilon}(e) \geq p_{1}(2 \beta-1)+p_{\theta}\left(2 \beta \theta-\theta^{2}\right), \\ \text { Overturn: } r=1 & \text { otherwise }\end{cases}
$$

Equation 2 shows that the overseer upholds agency-made policy following procedural review if and only if the precision improvement given the agency's effort investment (i.e., $V_{\varepsilon}(0)-V_{\varepsilon}(e)$ ) outweighs the net substantive policy losses, given her bias, if she upholds.

The condition to uphold the agency is more likely to be satisfied when the agency has invested high effort. Thus, there are two thresholds for upholding the agency based on the overseer's bias. Specifically, rearranging the condition for the overseer to uphold shows that the overseer's bias cannot be too large in order for the agency to receive deference: $\beta \in\left(0, \frac{p_{1}+p_{\theta} \theta^{2}+V_{\varepsilon}(0)-V_{\varepsilon}(e)}{2\left(p_{1}+p_{\theta} \theta\right)}\right]$. The upper bound of overseer bias in which she will still uphold the agency is a function of agency effort (as it feeds into $V_{\varepsilon}(e)$ ). Let $\beta_{0}$ be the upper bound when the agency has invested low effort and $\beta_{1}$ 
represent the upper bound when the agency has invested high effort. Since implementation variance is lower when the agency invests high effort $\beta_{1}>\beta_{0}$, implying that oversight is more stringent when the agency has invested low effort. ${ }^{23}$ That is, when the agency invested high effort it will be upheld for a wider range of agency-overseer policy disagreement than if it had invested low effort.

Where the overseer's bias lies relative to these two thresholds dictates the review regime the agency faces. When $\beta<\beta_{0}<\beta_{1}$ the overseer will always uphold the agency regardless of effort investment; she is perfectly deferential. On the other extreme, when $\beta>\beta_{1}>\beta_{0}$ the overseer will always overturn the agency regardless of effort; she is perfectly skeptical. Finally, when $\beta_{0}<\beta<\beta_{1}$ the overseer upholds the agency if and only if the agency invests high effort and the review regime is conditionally-deferential. Agency effort decisions depend crucially on these review regimes.

Perfectly deferential review. When the agency faces a perfectly deferential overseer it will be upheld whether or not it invests high effort. Thus, the only consideration from the agency's perspective is how much investing high effort will improve implementation relative to low effort, and whether that improvement is worth the cost of doing so:

$$
\underbrace{V_{\varepsilon}(0)-V_{\varepsilon}(1)}_{\text {precision improvement }} \geq \underbrace{\kappa .}_{\text {effort cost }}
$$

The more that investing high effort improves the precision of implemented policy outcomes the more likely it is bearing the cost of that effort will benefit the agency.

Perfectly skeptical review. If the agency is facing a perfectly skeptical overseer it never invests high effort. When the overseer is so biased that the agency cannot 'work hard enough' to appease her, high effort investment generates a net loss equal to the costs of that effort. Since the agency is overturned with certainty whether or not it invests high effort, the status quo will remain in place either way. Thus, the agency is better off avoiding high effort costs and investing low effort instead.

Conditional-deference review. The most interesting case is when the overseer is conditionallydeferential. In this case the agency decides between investing low effort and avoiding the effort

\footnotetext{
${ }^{23}$ The upper bound on overseer bias when the agency invests low effort is $\beta_{0} \equiv \frac{p_{1}+p_{\theta} \theta^{2}}{2\left(p_{1}+p_{\theta} \theta\right)}$ and the upper bound when the agency invests high effort is $\beta_{1} \equiv \frac{p_{1}+p_{\theta} \theta^{2}+V_{\varepsilon}(0)-V_{\varepsilon}(1)}{2\left(p_{1}+p_{\theta} \theta\right)}$. $V_{\varepsilon}(1)<V_{\varepsilon}(0)$ implies $\beta_{0}<\beta_{1}$.
} 
costs at the expense of the reversal cost, and investing high effort, which leads to being upheld and avoiding the reversal cost but comes at the expense of high effort costs. Since the agency does not yet know $\omega$ when it chooses effort it must also take into account the probability distribution $\mathbf{p}$ over potential states of the world. Specifically, when the agency invests low effort it knows it will be overturned, but since it does not yet know the state it does not know exactly how costly doing so will be from a substantive policy perspective. With this in mind, the agency's subjective expected payoff for investing low effort is given by,

$$
-p_{1}-p_{\theta} \theta^{2}-V_{\varepsilon}(0)-\pi
$$

If the agency invests low effort then, in expectation, it loses utility based on the probability of each state and the losses associated with having $x=0$ with expected implementation error $V_{\varepsilon}(0)$ as well as having to pay the reversal cost $\pi$.

If instead the agency invests high effort it will be upheld and therefore be able to match policy to the state and avoid paying the reversal cost, but it will have to bear the costs of the expected imprecision of realized outcomes $V_{\varepsilon}(1)$ and pay the cost of effort $\kappa$ :

$$
-V_{\varepsilon}(1)-\kappa
$$

Combining and rearranging these two subjective expected payoffs yields the condition that must be met in order for the agency to optimally invest high effort when facing conditional deference:

$$
p_{1}+p_{\theta} \theta^{2}+V_{\varepsilon}(0)-V_{\varepsilon}(1)+\pi \geq \kappa \text {. }
$$

The left-hand side of this inequality captures the net benefits of investing high effort and being upheld while the right-hand side captures the cost, $\kappa$, of doing so. The more punitive the reversal costs (i.e., higher $\pi$ ) the easier it is to satisfy this expression. Similarly, the more precise high effort policy is (i.e., lower $\left.V_{\varepsilon}(1)\right)$ the higher the cost the agency will bear to invest that into implementation. 


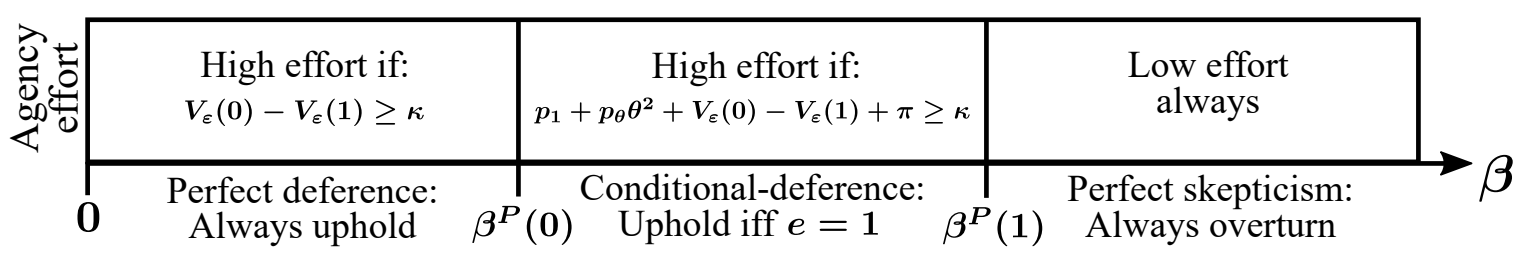

Figure 1: Equilibrium procedural review and agency effort

Taken together, the preceding analysis characterizes the equilibrium to the procedural review model, stated in the following result and represented graphically in Figure 1.

Proposition 1. In the procedural review model the overseer makes review decisions according to $s_{R}^{*}(e)$ (equation 2), the agency always sets substantive policy to match the state and invests effort, conditional on review regime, as follows: When facing a perfectly deferential overseer the agency invests high effort when $V_{\varepsilon}(0)-V_{\varepsilon}(1) \geq \kappa$. When facing a perfectly skeptical overseer the agency never invests high effort. When facing a conditional-deference overseer the agency invests high effort if $p_{1}+p_{\theta} \theta^{2}+V_{\varepsilon}(0)-V_{\varepsilon}(1)+\pi \geq \kappa$.

Proposition 1 illustrates that effort incentives are strongest under conditional-deference review. The range of costs such that the agency would invest high effort is larger when the overseer is conditionally-deferential compared to perfectly deferential. Substantively, this highlights a strength of intermediately skeptical oversight (i.e., conditionally-deferential). It creates a situation in which agency effort incentives are strong precisely because the agency needs to work hard on developing the capacity to implement policy well in order to enjoy substantive discretion (i.e., match policy to the state). In turn, this means the agency is willing to pay higher costs to develop that capacity in order to enjoy that discretion. Interestingly, this is distinct from previous research showing that discretion can be used to incentivize effort from bureaucrats (e.g., Gailmard and Patty 2007). In this case, effort is invested by the agency to create its own substantive discretion in the face of ex post review. As we will see in the substantive review model a similar, but more nuanced, implication also emerges in that setting. 


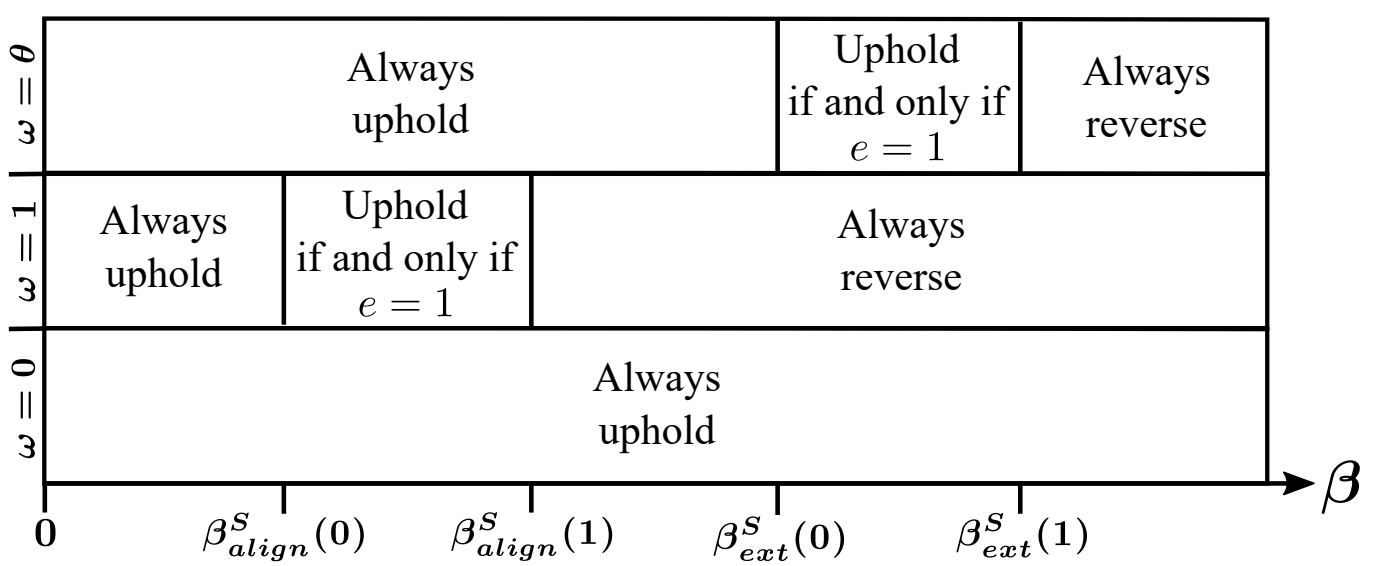

Figure 2: Overseer best responses to truthful policymaking given $\omega$ and $\beta$

Note: Aligned preferences are when $\beta<\beta_{\text {align }}^{S}(0)=1 / 2$, conditionally aligned preferences are when $1 / 2=\beta_{\text {align }}^{S}(0)<\beta<\beta_{\text {align }}^{S}(1)=\frac{1+V_{\varepsilon}(0)-V_{\varepsilon}(1)}{2}$, moderate preferences are when $\frac{1+V_{\varepsilon}(0)-V_{\varepsilon}(1)}{2}=$ $\beta_{\text {align }}^{S}(1)<\beta<\beta_{\text {ext }}^{S}(0)=\frac{\theta^{2}}{2 \theta}$, conditionally extreme preferences are when $\frac{\theta^{2}}{2 \theta}=\beta_{\text {ext }}^{S}(0)<\beta<$ $\beta_{\text {extreme }}^{S}(1)=\frac{\theta^{2}+V_{\varepsilon}(0)-V_{\varepsilon}(1)}{2 \theta}$, and extreme preferences are when $\beta>\beta_{\text {ext }}^{S}(1)$.

\section{Judging substance}

In the substantive review model the overseer now has the additional information of the agency's substantive policy choice $x_{A}$, which may reveal information about $\omega$. Could this additional information harm the overseer? That is, can allowing the overseer to judge the substantive content of the agency's policy, in addition to monitoring investments in procedural capacity, lead to worse outcomes compared to restricting her to purely procedural review? Before addressing these questions directly I discuss how this richer oversight environment affects agency policymaking in equilibrium.

I first analyze whether and when the agency will set substantive policy 'truthfully.' A truthful policymaking strategy for the agency corresponds to behavior in a separating equilibrium and is denoted by $x_{A}^{\text {truth }}(\omega)=\omega$. If the agency is truthful then the overseer learns $\omega$ perfectly. This can be thought of as a normative benchmark in the sense that if the agency was authorized to make policy due to its policy-relevant expertise, this is a case in which the agency fully utilizes that expertise. Given $x_{A}^{\text {truth }}(\omega)$ the overseer's review strategy is illustrated in Figure 2.

Figure 2 shows that the overseer will always uphold the agency when she learns that $\omega=0$ 
and that as overseer-agency preference divergence grows (i.e., as $\beta$ increases) it is more difficult for the agency to be upheld following truthful policymaking. The overseer always upholds a truthful agency following $x_{A}=0$ because either way the spatial location of policy will be $x=0$ and either the agency invested low effort, in which case the expected implementation shock is the same as when she overturns, or high effort in which case she is strictly better off upholding due to the implementation improvement from the agency's effort. ${ }^{24}$ Substantively, this implies that when the overseer learns that the state of the world calls for maintenance of the status quo the overseer is fine allowing the agency to continue doing so with full deference. Further, the figure illustrates that it is more difficult for the agency to receive deference following truthful policymaking when the overseer's bias increases. $^{25}$

Compared to the procedural review model there is now no case in which the overseer is perfectly skeptical. However, if the overseer is sufficiently unbiased then she becomes perfectly deferential. Since the thresholds on $\beta$ listed in the table are endogenous to the agency's effort decisions there are ranges of biases in which the overseer is conditionally-deferential and upholds the agency if and only if $e=1$ following particular choices of $x_{A}$. Specifically, this is when the agency and overseer are conditionally aligned, $\beta \in\left(\beta_{\text {align }}^{S}(0), \beta_{\text {align }}^{S}(1)\right)$, or preference misalignment is conditionally extreme, $\beta \in\left(\beta_{\text {ext }}^{S}(0), \beta_{\text {ext }}^{S}(1)\right)$. One immediate difference across the two types of review is that now when the agency always matches policy to the state the overseer learns the agency's private information about $\omega$, which eliminates the agency's expertise advantage. Accordingly, there is now no guarantee that the agency will be able to set policy truthfully and avoid reversal. Indeed, there are only limited circumstances in which that is feasible; namely, when agency-overseer preferences are sufficiently aligned given effort investment $e: \beta \leq \beta_{\text {align }}^{S}(e)$.

\footnotetext{
${ }^{24}$ It is worth noting that when the agency invests low effort and truthfully reveals that $\omega=0$ by setting $x_{A}=0$ that the overseer is indifferent so I am assuming that indifference is broken in the direction of agency deference. Formally, even a small cost for the overseer to reverse (for example if reversal requires more thorough justification than simply deferring and allowing the agency to operate based on its own existing determinations) would break this indifference in the direction of deference and produce this same behavior in equilibrium. Given the general impression in the literature that overseers such as courts are generally deferential to administrative agencies this is a reasonable way to break that indifference.

${ }^{25}$ The thresholds are computed similar to those from the procedural review model (i.e., from overseer incentive compatibility conditions) and can be found in Section B.1 of the Online Appendix.
} 
Proposition 2. There is a truthful separating equilibrium in which the agency always reveals the state by setting $x_{A}^{*}(\omega)=\omega$ if and only if overseer-agency preferences are sufficiently aligned: $\beta<$ $\beta_{\text {align }}^{S}(e)$, where $\beta_{\text {align }}^{S}(0)<\beta_{\text {align }}^{S}(1)$. There is also a pooling to placate equilibrium in which the agency sets $x_{A}^{*}(\omega)=0$ for all $\omega$ any time preference divergence is sufficiently extreme: $\beta>\beta_{\text {ext }}^{S}(e)$, where $\beta_{\text {ext }}^{S}(0)<\beta_{\text {ext }}^{S}(1)$.

Proposition 2 also shows that when preference disagreement is extreme, $\beta>\beta_{\text {ext }}^{S}(e)$, the agency will never fully reveal $\omega$. This is because it is better to set $x_{A}=0$ to avoid reversal, and the associated $\operatorname{cost} \pi$, and since the overseer would reverse any $x_{A} \neq 0$ this leads to a pooling equilibrium. In particular, the agency will match policy to the state when $\omega=0$, but otherwise, when $\omega \in\{1, \theta\}$, it will placate the overseer by always setting policy at $x=0$ to avoid being reversed. I refer to the two types of equilibria in Proposition 2 as truthful separating equilibrium and pooling to placate equilibrium, respectively. In the former policymaking is fully responsive to the state, while in the latter policymaking is fully unresponsive due to extreme policy disagreement. Thus, closely aligned preferences allow the agency to fully utilize its private information while extremely divergent preferences lead to agency to totally disregard its private information. In both cases the agency sets policy perfectly in line with the overseer's (induced) preferences given her bias.

When preference disagreement is moderate and the overseer would reverse the agency for truthfully revealing that $\omega=1$ (by setting $x_{A}(1)=1$ ) the agency can avoid reversal by obfuscating with its policy choice and setting policy at $x_{A} \in\{0, \theta\}$. The dynamics in these semi-pooling obfuscation equilibria are more nuanced than in the cases of Proposition 2.

\subsection{Obfuscation equilibria}

When it comes to partially responsive obfuscation equilibria in which the agency reveals some, but not all, information about $\omega$ there are two scenarios. The first is when the policy area $\theta$ is high urgency $(\theta>2)$. The second is when the policy area is low urgency $(\theta<2)$. The agency's equilibrium obfuscation behavior depends on which setting it is operating within. 


\subsubsection{Obfuscating to appease}

When $\theta>2$ the issue is high urgency and the agency would prefer to obfuscate when it learns that the state is moderate, $\omega=1$, by setting $x_{A}=0$. By doing so the agency appeases the overseer, who prefers $x_{A}=0$ when $\omega=1$ given moderately divergent preferences, and avoids reversal. The following result characterizes equilibrium review and policy choice in this environment.

Proposition 3. When $\theta>2$ and preference disagreement is such that $\beta \in\left(\beta_{\text {align }}^{S}(e), \beta_{\text {ext }}^{S}(e)\right)$ there is a semi-pooling equilibrium in which the agency obfuscates to appease by setting $x_{A}(\omega)=0$ for $\omega \in\{0,1\}$ and $x_{A}(\theta)=\theta$ and the overseer upholds $x_{A} \in\{0, \theta\}$ and reverses $x_{A}=1$.

In this equilibrium, which I refer to as obfuscating to appease, the agency is partially responsive to its information. It does match policy to the state when $\omega \in\{0, \theta\}$ but when moderate policy change is called for, $\omega=1$, the agency benefits by obfuscating. If the agency were to truthfully set policy so that $x_{A}(1)=1$ the overseer would reverse by virtue of having moderately biased preferences (as illustrated in Figure 2), leading to losses of $-1-\pi$ for the agency. If instead the agency were to set $x_{A}=0$ the overseer would uphold even if she knew for sure that $\omega=1$ since, given $\beta$, she would prefer $x=0$ anyway. This leads to a policy loss of -1 for the agency, but it can avoid paying the reversal $\operatorname{cost} \pi$. If instead the agency were to obfuscate by setting $x_{A}(1)=\theta$ then its losses would exceed -1 since $(\theta-1)^{2}>1$ when $\theta>2$. Thus, when the issue is high urgency and preference disagreement is moderate the agency will obfuscate when it learns that moderate policy change is called for by foregoing any policy change to satisfy the overseer.

The additional substantive review of the agency's policy choices, in this setting, leads the agency to eschew moderate policy change even though it believes doing so is justified according to its expertise. Instead it disregards that information and appeases the overseer to avoid reversal. From the overseer's perspective this is a desirable state of affairs. Indeed, the agency chooses her preferred policy in all states of the world. Policymaking is either all or nothing in this case: the status quo is maintained or extreme policy overhauls are pursued. 


\subsubsection{Obfuscating through exaggeration}

If $\theta<2$ so that the policy is low urgency, and preferences are moderately divergent, then the agency obfuscates through exaggeration by overstating the need for comprehensive policy change. Proposition 4 characterizes equilibrium policy choices and oversight in this environment. ${ }^{26}$

Proposition 4. When $\theta<2$, preference disagreement is such that $\beta \in\left(\beta_{\text {align }}^{S}(e), \beta_{\text {ext }}^{S}(e)\right)$, and $\omega=\theta$ is sufficiently likely relative to $\omega=1$ :

$$
\frac{p_{1}}{p_{1}+p_{\theta}} \leq \frac{\theta(\theta-2 \beta)+V_{\varepsilon}(0)-V_{\varepsilon}(e)}{2 \theta(\theta-1)},
$$

there is a semi-pooling equilibrium in which the agency obfuscates through exaggeration by setting $x_{A}(0)=0$ and $x_{A}(\omega)=\theta$ for $\omega \in\{1, \theta\}$ and the overseer upholds $x_{A} \in\{0, \theta\}$ and reverses $x_{A}=1$.

In contrast to the obfuscating to appease equilibrium, in this case the agency always prefers obfuscating through exaggeration because the issue is low urgency. When $\omega=1$ the agency would be overturned for truthfully setting $x_{A}(1)=1$, again leading to losses of $-1-\pi$. In contrast, if the agency were to instead set $x_{A}(1)=\theta$ then the agency can avoid being reversed (and therefore paying $\pi)$ and also minimize policy losses since $(\theta-1)^{2}<1$ when $\theta<2$. The agency 'raises the stakes' for the overseer to overturn by signaling that its expert information indicates that extreme policy intervention is warranted. For the overseer to uphold in this case it must be the case that the extreme state is sufficiently likely relative to the moderate state. The reason for this is that now the agency is obfuscating by moving policy further from the overseer's induced preference which, as in the case of obfuscating to appease, is no policy change. Thus, for the overseer's upholding $x_{A}=\theta$ to be a best response it must be that $\omega=\theta$ with a high enough likelihood to justify that deference. The risk of overturning when the state does actually call for extreme change needs to be high enough in order for the overseer to prefer upholding the agency even though she knows the agency might be

\footnotetext{
${ }^{26}$ I focus on pure strategies in the main text. If equation (3) does not hold, i.e., $\frac{p_{1}}{p_{1}+p_{\theta}}>\frac{\theta(\theta-2 \beta)+V_{\varepsilon}(0)-V_{\varepsilon}(e)}{2 \theta(\theta-1)}$, then this type of equilibrium involves mixed strategies. The agency mixes between $x_{A}(\omega)=0$ and $x_{A}(\omega)=\theta$ when $\omega=1$ and matches the state, $x_{A}(\omega)=\omega$, when $\omega \in\{0, \theta\}$, and the overseer upholds $x_{A}=0$, reverses $x_{A}=1$, and mixes between upholding and reversing $x_{A}=\theta$. This behavior is characterized in Proposition B.1 in the Online Appendix.
} 
exaggerating the need for such a large policy shift.

The need for extreme change being sufficiently likely relative to moderate change captures policy environments in which everyone believes ex ante that whenever policy changes are warranted substantial overhauls may be preferable to incremental, moderate ones. Returning to national security, this could be thought of as an environment in which, prior to any learning, government actors believe that a substantial revision of policies dictating relations with another country are likely to be called for given new national security information about the risks posed by that country. That is, there is a lot of weight placed on the possibility that new intelligence will reveal that the government ought to overhaul their approach to relations with a foreign power, as opposed to a moderate adjustment in foreign policy, in this environment. More generally, this is an ex ante concept so the main conceptual underpinnings of policy environments of this sort are that when actors believe change is likely to be warranted, sufficient weight is placed on the possibility that large changes might be the best route given the facts on the ground.

Overall, this highlights a key problem with allowing the overseer more information during review. Once the substance of policy is judged the agency may have incentive to exaggerate the need for policy change by pursuing extreme policy change when its private information suggests moderate change would suffice. This runs counter to many previous theories of bureaucratic oversight in which review of agency policy choices typically leads the agency to moderate its choices in the direction of the overseer (e.g., Epstein and O'Halloran 1999; Shipan 1997; Wiseman 2009). Rather than appease the overseer by shading policy toward the status quo, the agency exaggerates the need for policy change because it signals to the overseer that she runs the risk of large policy losses if she 'shuts the agency down.' Exaggerating in this way both signals that overturning will lead to large policy loss through policy-state mismatch and increases the utility of allowing the agency to intervene in the environment, which increases the overall expected utility from upholding. The preceding analysis highlights how substantive review affects the agency's substantive policy choices, and how that in turn impacts the overseer's ability to effectively monitor the agency. The next section discusses the impact of agency effort investments on these strategies. 


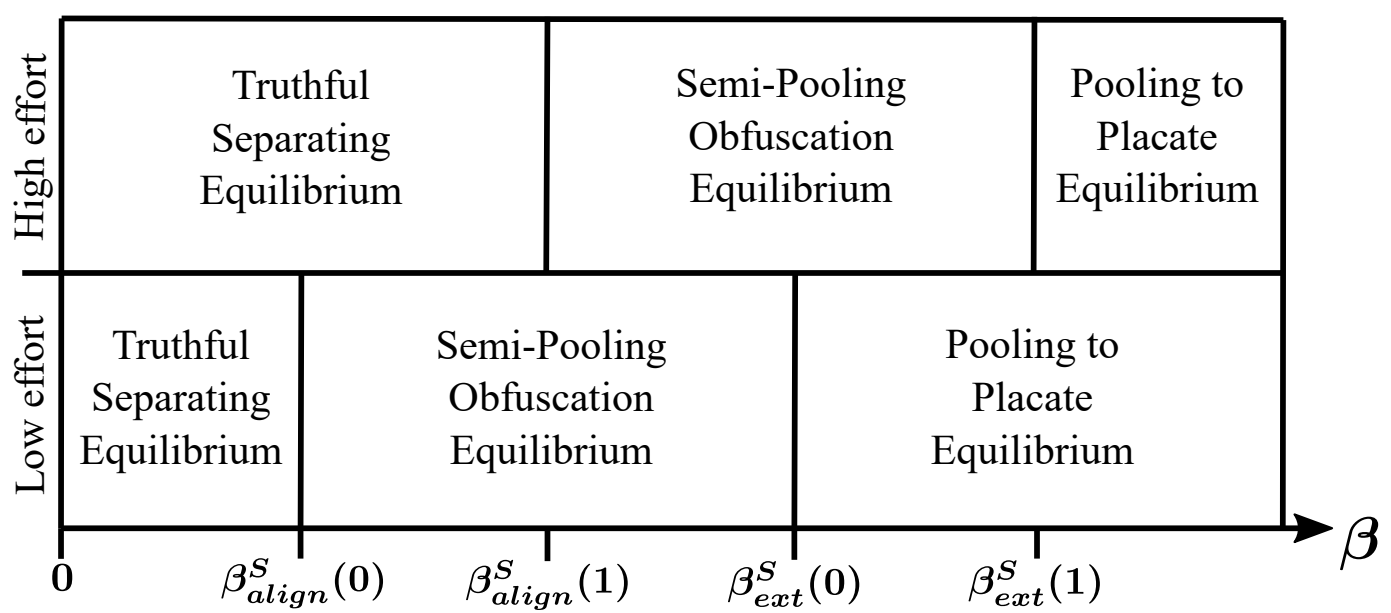

Figure 3: Equilibria under substantive review given agency effort and overseer bias

Note: The $\beta_{\text {align }}^{S}(e)$ and $\beta_{\text {ext }}^{S}(e)$ thresholds are as defined in Figure 2. In a truthful separating equilibrium the agency sets $x_{A}(\omega)=\omega$ for all $\omega$ while the overseer upholds all $x_{A}(\omega)$. In a semi-pooling obfuscation equilibrium the agency sets $x_{A}(\omega)=\omega$ for $\omega \in\{0, \theta\}$ but sets $x_{A}(1)=0$ when $\theta>2$ or $x_{A}(1)=\theta$ when $\theta<2$ while the overseer upholds $x_{A} \in\{0, \theta\}$ and overturns $x_{A}=1$. In a pooling to placate equilibrium the agency sets $x_{A}(\omega)=0$ for all $\omega$ while the overseer upholds $x_{A}=0$ and overturns $x_{A} \in\{1, \theta\}$.

\subsection{Working for discretion}

Similar to the way that high effort allows the agency to better match policy to the state under procedural review, high effort investments when the overseer can also judge the substance of policy lead to more agency discretion to set policy in line with its information. Lemma B.1 in the Online Appendix lays out all of the technical conditions for the agency to invest high effort given preference disagreement and the policymaking behavior outlined in the equilibria above. The general impact of high effort is straightforward in this setting. When the agency works hard to develop the capacity to implement policy effectively, the overseer is more likely to allow the agency to match policy to the state. This is illustrated graphically in Figure 3, which shows the type of equilibrium played for each level of preference disagreement and effort investment. ${ }^{27}$

Figure 3 shows that, first, when preferences are highly aligned the agency is always able to match policy to the state in a truthful separating equilibrium regardless of its effort investment. The

\footnotetext{
${ }^{27}$ See also Corollary B.1 in the Online Appendix.
} 
overseer, due to the fact she largely shares the agency's policy preferences, is not able to credibly threaten reversal even when the agency chooses low effort. As preference disagreement grows, however, oversight becomes more demanding. Once $\beta \in\left(\beta_{\text {align }}^{S}(0), \beta_{\text {align }}^{S}(1)\right)$, Figure 3 shows that high effort increases the agency's ability to respond to its information about $\omega$. Specifically, under low effort the agency will obfuscate by playing one of the semi-pooling strategies from Propositions 3 and 4 (depending on $\theta$ ) whereas under high effort the agency is able to continue to always match policy to the state. The high effort offsets some of the substantive policy losses incurred by the overseer by improving the expected efficacy of implementation (by reducing $V_{\varepsilon}(e)$ ), which leads to deference when it otherwise would not. Once the overseer's bias grows so that $\beta \in\left(\beta_{\text {align }}^{S}(1), \beta_{\text {ext }}^{S}(0)\right)$ even high effort will not offset the overseer's substantive policy losses when the state is $\omega=1$ so the agency obfuscates by semi-pooling regardless of effort. As preference disagreement grows extreme $\left(\beta \in\left(\beta_{\text {ext }}^{S}(0), \beta_{\text {ext }}^{S}(1)\right)\right)$ effort is once again consequential. Under low effort the agency is now induced to pool with $x_{A}=0$ for all $\omega$ in order to placate the overseer. However, if the agency invests high effort toward implementation then it is able to play a semi-pooling strategy (again, either to appease or through exaggeration, conditional on $\theta$ ) and match policy to the state to a greater degree than when it is fully unresponsive to its information under the pooling to placate equilibrium. That is, high effort buys the agency some discretion by again offsetting some of the spatial losses for the overseer through improved implementation. Finally, there is a point at which preference disagreement is so large that the agency always simply foregoes policy change at all, regardless of the state, because even investing high effort will not be enough to fend off reversal, which leads to the pooling to placate equilibrium.

This dynamic illustrates how oversight might serve to provide incentives for the agency to invest costly effort toward high quality policymaking. Interestingly, the agency works hard in order to create the discretion for itself to better influence the substantive content of policy. That is, by investing in the capacity to do its job well when implementing policy on the ground the agency buys itself some leeway with the overseer to set the substance of policy further from the overseer's preferred content without being sanctioned. This is complementary to other influential theories of 
policymaking in which substantive discretion is offered ex ante by political principals (or, overseers) to induce effort or expertise acquisition by agencies (e.g., Gailmard and Patty 2007). In this case, the agency investing in its own ability to administer policy effectively weakens the overseer's ability to use the threat of reversal as a tool to induce policy content closer to its preferred spatial location, thereby creating discretion through agency effort. This is similar to the idea that agencies work to develop reputations of high quality policy output that then insulates them from political interference as described in, for example, Carpenter (2001). ${ }^{28}$

\section{Reviewing procedure vs. judging substance}

Are there any circumstances under which increasing bureaucratic oversight harms the overseer by reducing bureaucratic accountability? That is, under what circumstances might the overseer benefit from only procedural review, as opposed to also being able to judge the substance of agency actions? From the overseer's perspective there are two salient dimensions to consider: agency effort and agency policy choice. Substantive review allows for greater control over the agency's spatial choices, but may induce obfuscation. Procedural review precludes that control, but due to allowing the agency to always match policy to the state may strengthen effort investment incentives. Proposition 5 below highlights environments in which the additional information provided through substantive review can harm overseer welfare, and shows that there are settings in which pure procedural review is optimal.

In the extreme cases of highly aligned and highly misaligned preferences, allowing for substantive review is inconsequential or weakly beneficial, respectively, in terms of overseer welfare. When preferences are very closely aligned the agency always matches policy to the state and effort incentives are identical so the overseer's welfare is unaffected regardless of the scope of review. When preferences are extremely divergent final policy is always spatially located at zero, ${ }^{29}$ but the agency never invests high effort under procedural review and may do so when the overseer judges

\footnotetext{
${ }^{28}$ Of course, these reputations are developed over the creation and application of many policies over time, which is outside of the model analyzed here. But, the general intuition underlying how high effort investments that improve overall outcomes allow for more impact on the substance of policy post investment is reminiscent of this dynamic.

${ }^{29}$ Under procedural review the agency is always overturned and under substantive review the agency pools to placate.
} 
substance if $\kappa$ is low enough, which implies that overseer welfare can be improved by substantive review when policy disagreement is extreme.

The interesting case from the perspective of institutional design is when policy disagreements are moderate, which leads to conditional-deference procedural oversight and semi-pooling obfuscation when substantive oversight is employed, the nature of which - obfuscation to appease or obfuscation through exaggeration - further depends on $\theta$. Proposition 5 characterizes overseer welfare in these cases.

Proposition 5. Suppose $\beta \in\left(\beta^{P}(0), \beta^{P}(1)\right), \beta \in\left(\beta_{\text {align }}^{S}(1), \beta_{\text {ext }}^{S}(0)\right)$, and equation (3) is satisfied so that procedural review is conditionally-deferential and substantive review always leads to a semipooling obfuscation equilibrium. If $\theta>2$ then the agency obfuscates to appease and overseer welfare is higher under procedural review if and only if effort costs are intermediate, $\kappa^{S}<\kappa<\kappa^{P}$, and $V_{\varepsilon}(0)-V_{\varepsilon}(1)>p_{1}(2 \beta-1)$. If $\theta<2$ then the agency obfuscates through exaggeration and overseer welfare is always higher under procedural review.

In the first case of Proposition 5 substantive oversight induces the agency to obfuscate to appease. This benefits the overseer by leading the agency to choose $x_{A}=0$ in the moderate state $\omega=1$, which is exactly what the overseer would prefer the agency do. In this case the ability to judge substance is attractive to the overseer. However, in this environment high effort is always more likely under procedural review so it is possible to offset this benefit when costs $\kappa$ are such that the agency invests high effort only under procedural review, which is when effort costs are moderate (i.e., $\kappa^{S}<\kappa<\kappa^{P}$ ). ${ }^{30}$ The obfuscation to appease induced by substantive review weakens effort incentives which will sometimes mean that the agency invests high effort when it is able to always match policy to the state (i.e., under pure procedural review), but invest low effort when it is induced to obfuscate (i.e., under substantive review). In that case if the value of that effort $\left(V_{\varepsilon}(0)-V_{\varepsilon}(1)\right)$ outweighs the cost of sacrificing the ability to judge substance and induce welfareimproving obfuscation $\left(p_{1}(2 \beta-1)\right)$ then the overseer's welfare is higher under procedural review.

\footnotetext{
${ }^{30}$ Formally, $\kappa^{P}=p_{1}+p_{\theta} \theta^{2}+V_{\varepsilon}(0)-V_{\varepsilon}(1)$ and $\kappa^{S}=V_{\varepsilon}(0)-V_{\varepsilon}(1)$ so $\kappa^{S}<\kappa^{P}$. This implies that when costs are intermediate, $\kappa \in\left(\kappa^{S}, \kappa^{P}\right)$, the agency chooses $e=1$ only under procedural review. See Lemmas A.3 and B.1 in the Online Appendix for more detailed derivations.
} 
In all other cases, however, when $\theta>2$ the overseer benefits from the ability to engage in substantive review and induce the agency to obfuscate to appease.

In the second case when $\theta<2$ the addition of substantive review induces the agency to obfuscate through exaggeration. In this environment the overseer never benefits from the added ability to judge substance. Compared to procedural review there is only downside. Effort incentives are stronger under procedural review, just as when $\theta>2$ described above, but now there is no concomitant benefit of inducing the agency to choose the overseer-preferred policy when $\omega=1$. Now the agency is induced to exaggerate how important policy action is by choosing $x_{A}(1)=\theta$, compared to appeasing the overseer with $x_{A}(1)=0$ as before, which further harms overseer welfare. On both the effort and spatial policy dimensions having the ability to judge substance is worse for the overseer than purely procedural review. Thus, the overseer would prefer to eschew the ability to judge the substance of policy and have her hands tied to only review procedure in this environment.

Ultimately, this result shows that overseers can benefit from less information in the review process because sometimes increasing bureaucratic oversight reduces bureaucratic accountability. The additional ability to judge the substantive content of policy, as opposed to focusing solely on the procedural investments in implementing policy well, can induce agencies to react by misrepresenting the need for more comprehensive policy change than is called given their expert opinion. This suggests that it is not clear that expanding the scope of review, and providing overseers with more information during the review process, yields net benefits once one takes into account how that information disclosure alters upstream incentives for bureaucrats who possess that information. In some environments the overseer would prefer to be directed, through statutory language or the like, to only review procedure and be explicitly precluded from also judging substance.

\section{Conclusion}

I have presented a theory of how different types of oversight can produce different bundles of policymaking incentives to bureaucratic agencies. Pure procedural review may provide incentives for high effort by allowing the agency to more often utilize its expertise, but that comes at the cost of 
the overseer sacrificing greater control of substantive policy choices. The addition of substantive review can induce the agency to disregard policy-relevant information and exaggerate the need for substantial policy change to avoid having its policies reversed. Moreover, these perverse obfuscation incentives will arise for wider ranges of policy disagreement when the agency has worked hard in developing implementation capacity due to the discretion those effort investments create. A key insight, then, is that expanding the range of information available to overseers in the review process may harm the overseer by causing agencies to protect their effort investments through obfuscation. This potentially undercuts the normative rationale for delegation to expert agencies by inducing the agencies to underutilize their expertise in some political environments.

This also shows that political principals can benefit from less information in the oversight process when the probability that policy change is called for is high. This suggests that it may be beneficial to shield bureaucratic policy actions from substantive review when they are asked to regulate dynamic, volatile policy environments that require substantive policy adjustments frequently. An illustrative example is national security issues that require swift intervention based on perceived security threats. In those policy areas it is natural to think that when national security agencies believe they need to act they place considerable weight on comprehensive actions to guard against large downside risks. Precisely because of that aspect of the environment, when they are induced to obfuscate with their choices they may pursue more comprehensive action than their information suggests is necessary (i.e., obfuscate through exaggeration). Overall, the scope of review can have differential effects on the agency's policymaking incentives. While increasing bureaucratic oversight may seem unambiguously desirable the strategic effects of doing so can actually lead to reduced bureaucratic accountability.

\section{References}

Ashworth, Scott. 2012. "Electoral Accountability: Recent Theoretical and Empirical Work.” Annual Review of Political Science 15:183-201.

Bawn, Kathleen. 1995. "Political Control Versus Expertise: Congressional Choices about Adminis- 
trative Procedures.” American Political Science Review 89:62-73.

Bendor, Jonathan, Amihai Glazer and Thomas Hammond. 2001. “Theories of Delegation.” Annual Review of Political Science 4(1):235-269.

Bueno de Mesquita, Ethan and Matthew C. Stephenson. 2007. "Regulatory Quality under Imperfect Oversight.” American Political Science Review 101(3):605-620.

Callander, Steven. 2011. “Searching For Good Policies.” American Political Science Review 105(4):643-662.

Callander, Steven and Gregory J. Martin. 2017. "Dynamic Policymaking with Decay." American Journal of Political Science 61(1):50-67.

Cameron, Charles M. 2000. Veto Bargaining. New York, NY: Cambridge University Press.

Canes-Wrone, Brandice, Michael C. Herron and Kenneth W. Shotts. 2001. "Leadership and Pandering: A Theory of Executive Policymaking.” American Journal of Political Science 45(3):532-550.

Carpenter, Daniel P. 2001. The Forging of Bureacuratic Autonomy: Reputations, Networks, and Policy Innovation in Executive Agencies, 1862-1928. Princeton, NJ: Princeton University Press.

Clark, Tom S. 2016. “Scope and Precedent: Judicial Rule-making Under Uncertainty.” Journal of Theoretical Politics 28(3):353-384.

Epstein, David and Sharyn O’Halloran. 1999. Delegating Powers: A Transaction Cost Politics Approach to Policy Making Under Separate Powers. New York, NY: Cambridge University Press.

Fox, Justin. 2007. “Government Transparency and Policymaking.” Public Choice 131(1-2):23-44.

Fox, Justin and Georg Vanberg. 2014. "Narrow versus Broad Judicial Decisions.” Journal of Theoretical Politics 26(3):355-383.

Fox, Justin and Matthew C Stephenson. 2015. "The Welfare Effects of Minority-Protective Judicial Review." Journal of Theoretical Politics 27(4):499-521. 
Fox, Justin and Richard Van Weelden. 2012. "Costly Transparency.” Journal of Public Economics 96(1):142-150.

Gailmard, Sean. 2009. "Discretion Rather than Rules: Choice of Instruments to Control Bureaucratic Policy Making.” Political Analysis 17(1):25-44.

Gailmard, Sean and John W. Patty. 2007. "Slackers and Zealots: Civil Service, Policy Discretion, and Bureaucratic Expertise.” American Journal of Political Science 51(4):873-889.

Gailmard, Sean and John W. Patty. 2013a. "Formal Models of Bureaucracy." Annual Review of Political Science 15:353-377.

Gailmard, Sean and John W. Patty. 2013b. Learning While Governing: Expertise and Accountability in the Executive Branch. Chicago, IL: University of Chicago Press.

Gersen, Jacob E. and Matthew C. Stephenson. 2014. "Over-accountability.” Journal of Legal Analysis 6(2):185-243.

Groseclose, Tim and Nolan McCarty. 2001. “The Politics of Blame: Bargaining before an Audience.” American Journal of Political Science 45(1):100-119.

Hirsch, Alexander V. and Kenneth W. Shotts. 2015. “Competitive Policy Development.” American Economic Review 105(4):1646-1664.

Hirsch, Alexander V. and Kenneth W. Shotts. 2018. "Policy-Development Monopolies: Adverse Consequences and Institutional Responses.” Journal of Politics 80(4):1339-1354.

Hitt, Matthew P., Craig Volden and Alan E. Wiseman. 2017. "Spatial Models of Legislative Effectiveness.” American Journal of Political Science 61(3):575-590.

Huber, Gregory A. 2007. The Craft of Bureaucratic Neutrality: Interests and Influence in Government Regulation of Occupational Safety. New York, NY: Canbridge University Press. 
Huber, John D. and Nolan McCarty. 2004. "Bureaucratic Capacity, Delegation, and Political Reform." American Political Science Review 98(3):481-494.

Light, Paul C. 1991. Forging Legislation. New York, NY: W.W. Norton.

Lipsky, Michael. 1980. Street-Level Bureaucracy. New York, NY: Russell Sage Foundation.

Lowande, Kenneth and Rachel Augustine Potter. 2020. "Congressional Oversight Revisited: Politics and Procedure in Agency Rulemaking." Journal of Politics 83(1):401-408.

McCann, Pamela J., Charles R. Shipan and Yuhua Wang. 2021. "Measuring the Legislative Design of Judicial Review of Agency Actions." Unpublished manuscript. Harvard University .

URL: https://scholar.harvard.edu/files/yuhuawang/files/mccann_ shipan_and_wang_2021.pdf

McCarty, Nolan. 2017. “The Regulation and Self-Regulation of a Complex Industry." Journal of Politics 79(4):1220-1236.

Melnick, R. Shep. 1983. Regulation and the Courts: The Case of The Clean Air Act. Washington, D.C.: The Brookings Institution.

Melnick, R. Shep. 1994. Between the Lines: Interpreting Welfare Rights. Washington, D.C.: The Brookings Institution Press.

Miller, Gary J. 2005. “The Political Evolution of Principal-Agent Models.” Annual Review of Political Science 8:203-225.

Patty, John W. and Ian R. Turner. 2021. "Ex Post Review and Expert Policymaking: When Does Oversight Reduce Accountability?” Journal of Politics 83(1):23-39.

Potter, Rachel Augustine. 2019. Bending The Rules: Procedural Politicking in the Bureaucracy. Chicago, IL: University of Chicago Press. 
Prat, Andrea. 2005. “The Wrong Kind of Transparency.” American Economic Review 95(3):862877.

Shapiro, Sidney A. and Richard E. Levy. 1995. "Judicial Incentives and Indeterminacy in Substantive Review of Administrative Decisions.” Duke Law Journal 44(6):1051-1080.

Shipan, Charles R. 1997. Designing Judicial Review: Interest Groups, Congress, and Communications Policy. Ann Arbor, MI: University of Michigan Press.

Shipan, Charles R. 2000. “The Legislative Design of Judicial Review: A Formal Analysis.” Journal of Theoretical Politics 12(3):269-304.

Stephenson, Matthew C. 2006. "A Costly Signaling Theory of "Hard Look" Judicial Review." Administrative Law Review 58(4):753-814.

Ting, Michael M. 2011. “Organizational Capacity.” Journal of Law, Economics, \& Organization 27(2):245-271.

Turner, Ian R. 2017. "Working Smart and Hard? Agency Effort, Judicial Review, and Policy Precision.” Journal of Theoretical Politics 29(1):69-96.

Turner, Ian R. 2019. "Political Agency, Oversight, and Bias: The Instrumental Value of Politicized Policymaking." Journal of Law, Economics, \& Organization .

Verkuil, Paul R. 2002. “An Outcomes Analysis of Scope of Review Standards.” William \& Mary Law Review 44(2):679-735.

Wagner, Wendy. 2012. "Revisiting the Impact of Judicial Review on Agency Rulemakings: An Empirical Investigation.” William \& Mary Law Review 53(5):1717-1795.

Wiseman, Alan E. 2009. "Delegation and Positive-Sum Bureaucracies." Journal of Politics 71(3):998-1014. 


\title{
Online Appendix: \\ Reviewing Procedure vs. Judging Substance: How Increasing Bureaucratic Oversight Can Reduce Bureaucratic Accountability \\ Journal of Political Institutions and Political Economy
}

\author{
Ian R. Turner \\ Department of Political Science \\ Yale University \\ ian.turner@yale.edu
}

\section{Contents}

A Procedural review model 1

A.1 Equilibrium policy choice . . . . . . . . . . . . . . . . 1

A.2 Equilibrium oversight . . . . . . . . . . . . . . . . 2

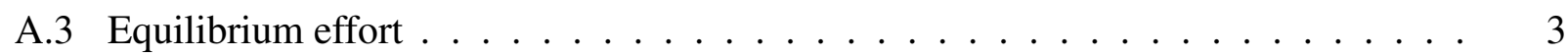

B Substantive review model $\quad 5$

B.1 Derivation of overseer best responses to truthful policymaking . . . . . . . . 5

B.2 Truthful separating equilibrium and pooling to placate . . . . . . . . . . 8

B.3 Semi-pooling obfuscation equilibria . . . . . . . . . . . . . . . 9

B.3.1 Obfuscating to appease . . . . . . . . . . . . . 9

B.3.2 Obfuscation through exaggeration .............. 10

B.4 Equilibrium effort . . . . . . . . . . . . . . . . 13

$\begin{array}{ll}\text { C Reviewing procedure vs. judging substance } & 16\end{array}$ 


\section{A Procedural review model}

\section{A.1 Equilibrium policy choice}

Lemma A.1. In the procedural review model the agency always matches policy to the state in weakly undominated pure strategies: $x_{A}^{P}(\omega)=\omega$.

Proof of Lemma A.1. At the point in the game at which the agency makes its substantive policy choice, $x_{A}$, its effort investment $e$ is a sunk cost. Thus, $e$ and $V_{\varepsilon}(e)$ are fixed. Additionally, since $x_{A}$ is not observed by the overseer the overseer's review decision is invariant to the agency's choice. Thus, there are two cases to check: (1) agency will be overturned and (2) agency will be upheld.

Case 1: Agency overturned. The agency's payoff in this case is equivalent regardless of its policy choice since the overseer's review decision is unaffected by the agency's choice of $x_{A}$. Thus, the agency has no reason to deviate from setting policy to match the state.

Case 2: Agency upheld. The agency's expected payoff for the proposed strategy is given by,

$$
\begin{aligned}
E U_{A}\left(x_{A}^{P}(\omega)=\omega \mid e, r=0\right) & =-(\omega-y)^{2}-\kappa e-\pi r, \\
& =-(\omega-(1)(\omega+\varepsilon(e)))^{2}-\kappa e, \\
& =-\mathbb{E}[\varepsilon]^{2}-V_{\varepsilon}(e)-\kappa e, \\
& =-V_{\varepsilon}(e)-\kappa e .
\end{aligned}
$$

Now suppose the agency deviated by choosing $x_{A}(\omega)=\omega+1\left(x_{A}(\omega)=\omega-1\right.$ is similar $)$. Its expected payoff for doing so is given by,

$$
\begin{aligned}
E U_{A}\left(x_{A}(\omega)=\omega+1 \mid e, r=0\right) & =-(\omega-(\omega+1+\varepsilon(e)))^{2}-\kappa e, \\
& =-(\omega-(\omega+1))^{2}-\mathbb{E}[\varepsilon]^{2}-V_{\varepsilon}(e)-\kappa e, \\
& =-1-V_{\varepsilon}(e)-\kappa e .
\end{aligned}
$$

Thus, the net expected utility for deviation is given by,

$$
\begin{aligned}
\Delta E U_{A}\left(x_{A}(\omega)=\omega+1 \mid e, r=0\right) & =-1-V_{\varepsilon}(e)-\kappa e+V_{\varepsilon}(e)+\kappa e, \\
& =-1,
\end{aligned}
$$

implying a net utility loss equal to the policy choice deviation. Thus, the agency is strictly worse off by deviating from the proposed strategy when the overseer will uphold the agency. Taken together these two cases imply that, in weakly undominated pure strategies, the agency will always choose $x_{A}^{P}(\omega)=\omega$ in the procedural review model. 


\section{A.2 Equilibrium oversight}

Lemma A.2. The overseer's optimal review strategy in the procedural review model is,

$$
s_{R}(e)= \begin{cases}\text { Uphold: } r=0 & \text { if } V_{\varepsilon}(0)-V_{\varepsilon}(e) \geq p_{1}(2 \beta-1)+p_{\theta}\left(2 \beta \theta-\theta^{2}\right) \\ \text { Overturn: } r=1 & \text { otherwise }\end{cases}
$$

Proof of Lemma A.2. Note that from Lemma A.1 we have that $x_{A}^{*}(\omega)=\omega$. First, consider the overseer's expected payoff for upholding the agency following a choice of $e$ :

$$
\begin{aligned}
E U_{R}\left(r=0 \mid e, \beta, x_{A}^{*}\right) & =-\left(\omega-\beta-\left(x_{A}^{*}+\varepsilon(e)\right)\right)^{2} \\
& =-(\omega-\beta-\omega)^{2}-\mathbb{E}[\varepsilon]^{2}-V_{\varepsilon}(e), \\
& =-\beta^{2}-V_{\varepsilon}(e)
\end{aligned}
$$

Now, the overseer's expected payoff for reversing the agency depends on the state $\omega$, which is unknown to the overseer in the procedural review model. For any given $\omega$ the overseer's expected payoff for reversal is given by:

$$
\begin{aligned}
E U_{R}(r=1 \mid e, \beta, \omega) & =-(\omega-\beta-(0+\varepsilon(0)))^{2} \\
& =-(\omega-\beta)^{2}-\mathbb{E}[\varepsilon]^{2}-V_{\varepsilon}(0), \\
& =-(\omega-\beta)^{2}-V_{\varepsilon}(0)
\end{aligned}
$$

Plugging this in for each $\omega$, scaled by the overseer's beliefs about each state having obtained, which is given by $\mathbf{p}=\left\{p_{0}, p_{1}, p_{\theta}\right\}$, we have the overseer's overall expected payoff for overturning:

$$
\begin{aligned}
E U_{R}(r=1 \mid e, \beta, \mathbf{p}) & =-p_{0}\left((0-\beta)^{2}+V_{\varepsilon}(0)\right)-p_{1}\left((1-\beta)^{2}+V_{\varepsilon}(0)\right)-p_{\theta}\left((\theta-\beta)^{2}+V_{\varepsilon}(0)\right) \\
& =-p_{0} \beta^{2}-p_{1}(1-\beta)^{2}-p_{\theta}(\theta-\beta)^{2}-V_{\varepsilon}(0)
\end{aligned}
$$

Incentive compatibility requires that the overseer uphold $(r=0)$ if and only if:

$$
\begin{aligned}
& E U_{R}\left(r=0 \mid e, \beta, x_{A}^{*}\right) \geq E U_{R}(r=1 \mid e, \beta, \mathbf{p}), \\
& \quad-\beta^{2}-V_{\varepsilon}(e) \geq-p_{0} \beta^{2}-p_{1}(1-\beta)^{2}-p_{\theta}(\theta-\beta)^{2}-V_{\varepsilon}(0), \\
& \quad-\beta^{2}-V_{\varepsilon}(e) \geq-p_{0} \beta^{2}-p_{1}+2 \beta p_{1}-p_{1} \beta^{2}-p_{\theta} \beta^{2}+2 \beta \theta p_{\theta}-p_{\theta} \theta^{2}-V_{\varepsilon}(0), \\
& V_{\varepsilon}(0)-V_{\varepsilon}(e) \geq p_{1}(2 \beta-1)+p_{\theta}\left(2 \beta \theta-\theta^{2}\right),
\end{aligned}
$$

as stated in the result. 
Now, recall the definitions derived from the overseer's incentive compatibility constraint to uphold. That is, it must be the case that $\beta \in\left(0, \frac{p_{1}+p_{\theta} \theta^{2}+V_{\varepsilon}(0)-V_{\varepsilon}(e)}{2\left(p_{1}+p_{\theta} \theta\right)}\right]$ for the overseer to uphold. We can define two $\beta$-thresholds based on whether the agency invested high or low effort: $\beta_{1} \equiv$ $\frac{p_{1}+p_{\theta} \theta^{2}+V_{\varepsilon}(0)-V_{\varepsilon}(1)}{2\left(p_{1}+p_{\theta} \theta\right)}$ and $\beta_{0} \equiv \frac{p_{1}+p_{\theta} \theta^{2}}{2\left(p_{1}+p_{\theta} \theta\right)}$ where $\beta_{0}<\beta_{1}$ since $V_{\varepsilon}(1)<V_{\varepsilon}(0)$.

If $\beta<\beta_{1}<\beta_{0}$ then the overseer always upholds and is perfectly deferential. If $\beta_{1}<\beta_{0}<\beta$ then the overseer always overturns and is perfectly skeptical. If $\beta_{1}<\beta<\beta_{0}$ then the overseer upholds if and only if $e=1$ and is conditionally deferential. The next result characterizes how the agency best responds with its effort choices conditional on these oversight regimes.

\section{A.3 Equilibrium effort}

Lemma A.3. Conditional on the overseer's bias $\beta$, the agency invests effort as follows:

1. If $\beta<\beta_{1}<\beta_{0}$ then the overseer is perfectly deferential and the agency invests high effort if $V_{\varepsilon}(0)-V_{\varepsilon}(1) \geq \kappa$.

2. If $\beta_{1}<\beta_{0}<\beta$ then the overseer is perfectly skeptical and the agency never invests high effort.

3. If $\beta_{1}<\beta<\beta_{0}$ then the overseer is conditionally deferential and the agency invests high effort if $p_{1}+p_{\theta} \theta^{2}+V_{\varepsilon}(0)-V_{\varepsilon}(1)+\pi \geq \kappa$.

Proof of Lemma A.3. I proceed by deriving the agency's incentive compatibility conditions to invest high effort given the type of review it is facing.

Case 1: $\beta<\beta_{0}<\beta_{1}$, perfect deference. In this case the agency knows that it will be upheld regardless of its choice of $e$. The agency's expected payoff, given it will be upheld for sure, for investing low effort is given by,

$$
\begin{aligned}
E U_{A}\left(e=0 \mid r=0, x_{A}(\omega)=\omega\right) & =-(\omega-(\omega+\varepsilon(0)))^{2}-\kappa(0)-\pi(0) \\
& =-(\omega-\omega)^{2}-\mathbb{E}[\varepsilon]^{2}-V_{\varepsilon}(0) \\
& =-V_{\varepsilon}(0)
\end{aligned}
$$

The agency's expected payoff for investing high effort is given by,

$$
\begin{aligned}
E U_{A}\left(e=1 \mid r=0, x_{A}(\omega)=\omega\right) & =-\left(\omega-(\omega+\varepsilon(1))^{2}-\kappa-\pi(0),\right. \\
& =-V_{\varepsilon}(1)-\kappa
\end{aligned}
$$

For the agency to invest high effort the following incentive compatibility constraint must be satisfied:

$$
\begin{aligned}
-V_{\varepsilon}(1)-\kappa & \geq-V_{\varepsilon}(0), \\
V_{\varepsilon}(0)-V_{\varepsilon}(1) & \geq \kappa .
\end{aligned}
$$


The precision improvement of investing high effort relative to low effort must outweigh the costs of doing so. This is case 1 in the result.

Case 2: $\beta_{0}<\beta_{1}<\beta$, perfect skepticism. In this case the agency will be reversed by the overseer with certainty, regardless of its choice of $e$. The agency will never invest high effort in this case since that would simply lead to a net loss proportional to the cost of that effort. To see why, consider the agency's expected payoff for investing low effort in this case,

$$
\begin{aligned}
E U_{A}(e=0 \mid r=1) & =-(\omega-\varepsilon(0))^{2}-\kappa(0)-\pi, \\
& =-\omega^{2}-V_{\varepsilon}(0)-\pi .
\end{aligned}
$$

The agency's expected payoff for investing high effort is given by,

$$
\begin{aligned}
E U_{A}(e=1 \mid r=1) & =-(\omega-\varepsilon(0))^{2}-\kappa-\pi, \\
& =-\omega^{2}-V_{\varepsilon}(0)-\kappa-\pi .
\end{aligned}
$$

Combining these expected payoffs yields the net expected payoff to the agency for investing high effort given that it will be overturned with certainty,

$$
\begin{aligned}
\Delta E U_{A}(e=1 \mid r=1) & =-\omega^{2}-V_{\varepsilon}(0)-\kappa-\pi+\omega^{2}+V_{\varepsilon}(0)+\pi, \\
& =-\kappa .
\end{aligned}
$$

Thus, it is never incentive compatible for the agency to invest high effort given that it will overturned by the overseer with certainty. This is case 2 in the result.

Case 3: $\beta_{0}<\beta<\beta_{1}$, conditional-deference. In this case the overseer upholds the agency if and only if the agency invests high effort. The agency's expected payoff for investing high effort, which induces being upheld, is given by,

$$
\begin{aligned}
E U_{A}\left(e=1 \mid r^{*}(1)=0, x_{A}^{*}(\omega)=\omega\right) & =-(\omega-(\omega+\varepsilon(1)))^{2}-\kappa(1)-\pi(0), \\
& =-(\omega-\omega)^{2}-\mathbb{E}[\varepsilon]^{2}-V_{\varepsilon}(1)-\kappa, \\
& =-V_{\varepsilon}(1)-\kappa .
\end{aligned}
$$


The agency's expected payoff for investing low effort, which induces being overturned, is given by,

$$
\begin{aligned}
E U_{A}\left(e=0 \mid r^{*}(0)=1\right) & =-(\omega-\varepsilon(0))^{2}-\kappa(0)-\pi(1), \\
& =-\mathbb{E}\left[\omega^{2}\right]-\mathbb{E}[\varepsilon]^{2}-V_{\varepsilon}(0)-\pi \\
& =-p_{0}\left(0^{2}\right)-p_{1}\left(1^{2}\right)-p_{\theta}\left(\theta^{2}\right)-V_{\varepsilon}(0)-\pi \\
& =-p_{1}-p_{\theta} \theta^{2}-V_{\varepsilon}(0)-\pi
\end{aligned}
$$

Combining and rearranging these expected payoffs yields the agency's incentive compatibility constraint to invest high effort when facing a conditional-deference overseer:

$$
\begin{aligned}
-V_{\varepsilon}(1)-\kappa & \geq-p_{1}-p_{\theta} \theta^{2}-V_{\varepsilon}(0)-\pi, \\
p_{1}+p_{\theta}+V_{\varepsilon}(0)-V_{\varepsilon}(1)+\pi & \geq \kappa .
\end{aligned}
$$

This yields case 3 in the result.

Proposition 1. In the equilibrium of the procedural review model the overseer makes review decisions according to $s_{R}(e)$ (equation 2), the agency always sets substantive policy to match the state and invests effort, conditional on review regime, as follows:

- When facing a perfectly deferential overseer (i.e., $\beta_{0}<\beta_{1}<\beta$ ) the agency invests high effort when $V_{\varepsilon}(0)-V_{\varepsilon}(1) \geq \kappa$.

- When facing a perfectly skeptical overseer (i.e., $\beta_{0}<\beta_{1}<\beta$ ) the agency never invests high effort.

- When facing a conditional-deference overseer (i.e., $\beta_{0}<\beta<\beta_{1}$ ) the agency invests high effort if $p_{1}+p_{\theta} \theta^{2}+V_{\varepsilon}(0)-V_{\varepsilon}(1)+\pi \geq \kappa$.

Proof of Proposition 1. The result follows from a straightforward combination of Lemma A.1, Lemma A.2, and Lemma A.3.

\section{B Substantive review model}

\section{B.1 Derivation of overseer best responses to truthful policymaking}

In this section I derive the overseer's best response function assuming that the agency always reveals $\omega$ by setting policy truthfully, $x_{A}(\omega)=\omega$. First, consider the overseer's expected utility for 


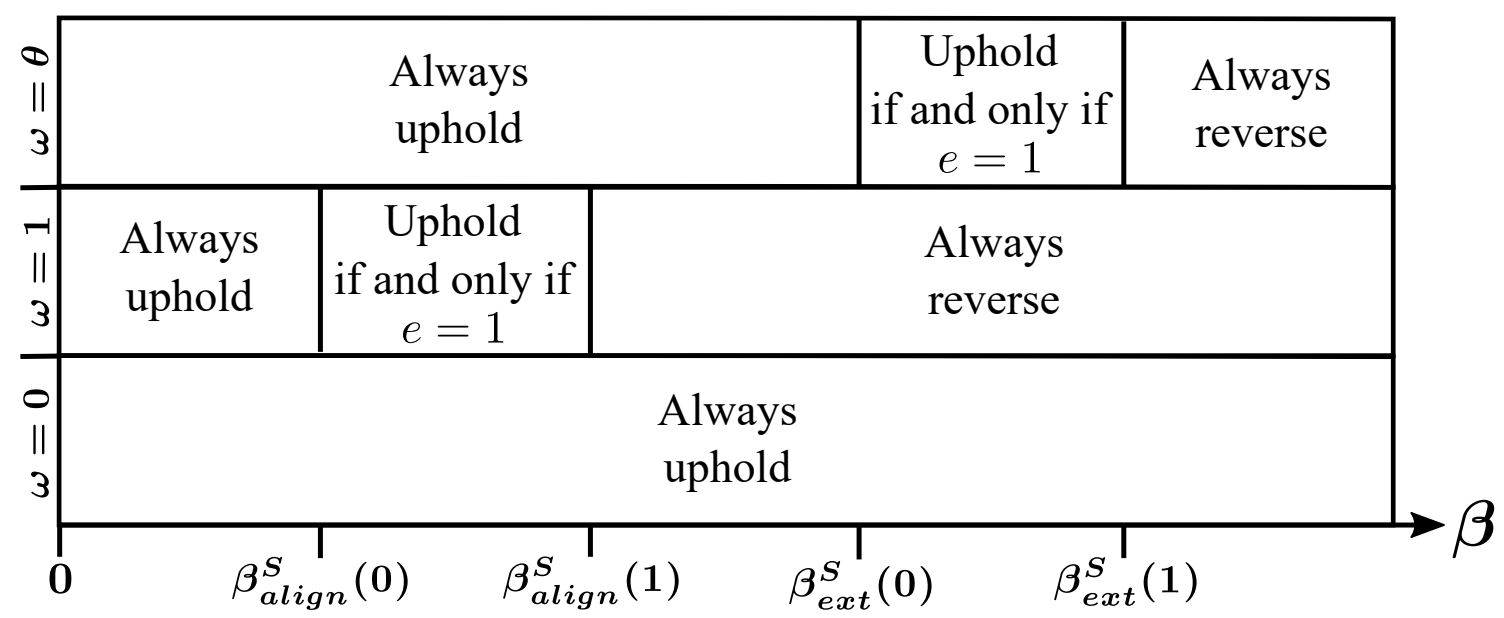

Figure 1: Overseer best responses to $x_{A}(\omega)=\omega$ given $\omega, \beta$, and $e$

Note: Aligned preferences are when $\beta<\beta_{\text {align }}^{S}(0)=1 / 2$, conditionally aligned preferences are when $1 / 2=\beta_{\text {align }}^{S}(0)<\beta<\beta_{\text {align }}^{S}(1)=\frac{1+V_{\varepsilon}(0)-V_{\varepsilon}(1)}{2}$, moderate preferences are when $\frac{1+V_{\varepsilon}(0)-V_{\varepsilon}(1)}{1}=$ $\beta_{\text {align }}^{S}(1)<\beta<\beta_{\text {ext }}^{S}(0)=\frac{\theta^{2}}{2 \theta}$, conditionally extreme preferences are when $\frac{\theta^{2}}{2 \theta}=\beta_{\text {ext }}^{S}(0)<\beta<$ $\beta_{\text {extreme }}^{S}(1)=\frac{\theta^{2}+V_{\varepsilon}(0)-V_{\varepsilon}(1)}{2 \theta}$, and extreme preferences are when $\beta>\beta_{\text {ext }}^{S}(1)$.

upholding the agency given $x_{A}(\omega)=\omega$ for any given $\omega$ and effort level $e$ :

$$
\begin{aligned}
E U_{R}\left(r=0 \mid x_{A}(\omega)=\omega, e\right) & =-\left(\omega-\beta-\left(x_{A}(\omega)+\varepsilon(e)\right)\right)^{2} \\
& =-(\omega-\beta-\omega)^{2}-\mathbb{E}[\varepsilon \mid e]^{2}-\operatorname{var}[\varepsilon \mid e], \\
& =-\beta^{2}-V_{\varepsilon}(e) .
\end{aligned}
$$

The analogous expected utilities for reversing the agency depend on $\omega$ and are given by:

$$
\begin{aligned}
E U_{R}(r=1 \mid \omega=0) & =-(0-\beta-\varepsilon(0))^{2} \\
& =-\beta^{2}-\mathbb{E}[\varepsilon \mid 0]^{2}-\operatorname{var}[\varepsilon \mid 0], \\
& =-\beta^{2}-V_{\varepsilon}(0), \\
E U_{R}(r=1 \mid \omega=1) & =-(1-\beta-\varepsilon(0))^{2} \\
& =-(1-\beta)^{2}-\mathbb{E}[\varepsilon \mid 0]^{2}-\operatorname{var}[\varepsilon \mid 0], \\
& =-(1-\beta)^{2}-V_{\varepsilon}(0), \\
E U_{R}(r=1 \mid \omega=\theta) & =-(\theta-\beta-\varepsilon(0))^{2} \\
& =-(\theta-\beta)^{2}-\mathbb{E}[\varepsilon \mid 0]^{2}-\operatorname{var}[\varepsilon \mid 0], \\
& =-(\theta-\beta)^{2}-V_{\varepsilon}(0) .
\end{aligned}
$$


Comparing the overseer's expected utilities for uphold versus reversing the agency in each state, which she knows for sure given the agency's separating strategy, yields the incentive compatibility conditions for the overseer to uphold. These in turn generate the bias thresholds in Figure 1. Consider first the case when $\omega=0$ :

$$
\begin{gathered}
r=0 \Longleftrightarrow E U_{R}(r=0 \mid 0, e) \geq E U_{R}(r=1 \mid 0), \\
-\beta^{2}-V_{\varepsilon}(e) \geq-\beta^{2}-V_{\varepsilon}(0), \\
V_{\varepsilon}(0)-V_{\varepsilon}(e) \geq 0
\end{gathered}
$$

which is always weakly satisfied since either $e=0$, in which case the inequality is satisfied with equality, or $e=1$, in which case the inequality holds strictly. Breaking indifference in the case of $e=0$ with deference to the agency ( $r=0$ when indifferent) implies that the overseer would always uphold the agency, regardless of $e$, when the agency truthfully reveals that $\omega=0$.

Consider now the case when $\omega=1$ :

$$
\begin{aligned}
r=0 \Longleftrightarrow E U_{R}(r=0 \mid 1, e) & \geq E U_{R}(r=1 \mid 1), \\
-\beta^{2}-V_{\varepsilon}(e) & \geq-(1-\beta)^{2}-V_{\varepsilon}(0), \\
\frac{1+V_{\varepsilon}(0)-V_{\varepsilon}(e)}{2} & \geq \beta .
\end{aligned}
$$

Thus, there are two bias cutoffs depending on agency effort for which the overseer would uphold the agency for truthfully setting $x_{A}(1)=1$ : (1) $e=0 \Rightarrow \beta_{\text {align }}^{S}(0):=\frac{1}{2}$ and (2) $e=1 \Rightarrow \beta_{\text {align }}^{S}(1):=$ $\frac{1+V_{\varepsilon}(0)-V_{\varepsilon}(1)}{2}$. Note that $\beta_{\text {align }}^{S}(0)<\beta_{\text {align }}^{S}(1)$ so that the overseer will uphold an agency that sets $x_{A}(1)=1$ for a wider range of preference disagreement when the agency exerts high effort. This generates the middle range in Figure 1 for when $\omega=1$. So long as the agency and overseer do not disagree too much (i.e., $\beta>\beta_{\text {align }}^{S}(1)$ ) then there is the possibility of the agency being upheld when the agency separates by setting policy truthfully, depending further on the agency's effort.

Finally, consider the case when $\omega=\theta$ :

$$
\begin{aligned}
r=0 \Longleftrightarrow E U_{R}(r=0 \mid \theta, e) & \geq E U_{R}(r=1 \mid \theta), \\
-\beta^{2}-V_{\varepsilon}(e) & \geq-(\theta-\beta)^{2}-V_{\varepsilon}(0), \\
\frac{\theta^{2}+V_{\varepsilon}(0)-V_{\varepsilon}(e)}{2 \theta} & \geq \beta .
\end{aligned}
$$

Thus, there is again two bias thresholds that dictate when $r=0$ following truthful policymaking when the agency plays a separating strategy: (1) $e=0 \Rightarrow \beta_{\text {ext }}^{S}(0):=\frac{\theta^{2}}{2 \theta}$ and (2) $e=1 \Rightarrow \beta_{\text {ext }}^{S}(1):=$ $\frac{\theta^{2}+V_{\varepsilon}(0)-V_{\varepsilon}(1)}{2 \theta}$. When $\beta>\beta_{\text {ext }}^{S}(e)$ preference divergence is sufficiently extreme, given $e$ and truthful 
policymaking, to lead the overseer to reverse the agency. Otherwise, the overseer upholds. This captures the top range in Figure 1 when $\omega=\theta$.

Taken together, the overseer's best response function given $x_{A}(\omega)=\omega$ for all $\omega$ is given by:

$$
s_{R}\left(x_{A}(\omega)=\omega, e\right)= \begin{cases}\text { Uphold: } r=0 & \text { if } x_{A}=0, \\ & \text { if } x_{A}=1 \text { and } \beta<\beta_{\text {align }}^{S}(e), \\ & \text { if } x_{A}=\theta \text { and } \beta<\beta_{\text {ext }}^{S}(e), \\ \text { Overturn: } r=1 & \text { otherwise. }\end{cases}
$$

\section{B.2 Truthful separating equilibrium and pooling to placate}

Proposition 2. There is a truthful separating equilibrium in which the agency always reveals the state by setting $x_{A}^{*}(\omega)=\omega$ if and only if overseer-agency preferences are sufficiently aligned: $\beta<\beta_{\text {align }}^{S}(e):=\frac{1+V_{\varepsilon}(0)-V_{\varepsilon}(e)}{2}$, where $\beta_{\text {align }}^{S}(0)<\beta_{\text {align }}^{S}(1)$. Moreover, there is a pooling to placate equilibrium in which the agency sets $x_{A}^{*}(\omega)=0$ for all $\omega$ any time preference divergence is sufficiently extreme: $\beta>\beta_{\text {ext }}^{S}(e):=\frac{\theta^{2}+V_{\varepsilon}(0)-V_{\varepsilon}(e)}{2 \theta}$, where $\beta_{\text {ext }}^{S}(0)<\beta_{\text {ext }}^{S}(1)$.

Proof of Proposition 2. Suppose that $\beta<\beta_{\text {align }}^{S}(e)$ so that, given $e$, the agency is upheld following $x_{A}(\omega)=\omega, \forall \omega$ (from Lemma A.2). Clearly in this case there is no reason for the agency to deviate from matching policy to the state since doing so will only lead to a net loss equal to the deviation. Suppose instead that $\beta>\beta_{\text {align }}^{S}(e)$, given $e$, so that the overseer reverses the agency when it truthfully reveals that $\omega=1$. In that case the agency can avoid reversal by deviating to $x=0$ given that the overseer will uphold according to $s_{R}\left(x_{A}(\omega)=\omega, e\right)$ from Lemma A.2, which is beneficial since:

$$
\begin{gathered}
E U_{A}\left(x_{A}(1)=1 \mid r(1, e)=1, \omega=1\right)<E U_{A}\left(x_{A}=0 \mid r(0, e)=0, \omega=1\right), \\
-(1-\varepsilon(e))^{2}-\kappa e-\pi<-(1-(0+\varepsilon(e)))^{2}-\kappa e \\
-1-\mathbb{E}[\varepsilon \mid 0]^{2}-\operatorname{var}[\varepsilon \mid 0]-\kappa e-\pi<-1-\mathbb{E}[\varepsilon \mid e]^{2}-\operatorname{var}[\varepsilon \mid e]-\kappa e \\
-1-V_{\varepsilon}(0)-\kappa e-\pi<-1-V_{\varepsilon}(e)-\kappa e \\
V_{\varepsilon}(e)-V_{\varepsilon}(0)<\pi
\end{gathered}
$$

which is satisfied for all $\pi>0$ given $V_{\varepsilon}(1)-V_{\varepsilon}(0)<0$ and $V_{\varepsilon}(0)-V_{\varepsilon}(0)=0$. Thus, the agency would always deviate from truthful policymaking when $\beta>\beta_{\text {align }}^{S}(e)$ to avoid reversal. Taken together this implies that the agency plays a separating strategy if and only preferences are sufficiently aligned: $\beta<\beta_{\text {align }}^{S}(e)$, as stated in the result.

Now suppose that preference disagreement is extreme: $\beta>\beta_{\text {ext }}^{S}(e)$. The overseer has a strictly dominant strategy of $r\left(x_{A}, e\right)=1$ for all $x_{A} \neq 0$ in this case. Given this, iterated elimination of 
dominated strategies yields $x_{A}^{*}(\omega)=0$ for all $\omega$ as the iteratively dominant strategy for the agent.

\section{B.3 Semi-pooling obfuscation equilibria}

\section{B.3.1 Obfuscating to appease}

Proposition 3. When $\theta>2$ and preference disagreement is such that $\beta \in\left(\beta_{\text {align }}^{S}(e), \beta_{\text {ext }}^{S}(e)\right)$ there is a semi-pooling equilibrium in which the agency obfuscates to appease by setting $x(\omega)=0$ for $\omega \in\{0,1\}$ and $x(\theta)=\theta$ and the overseer upholds $x_{A} \in\{0, \theta\}$ and reverses $x_{A}=1$.

Proof of Proposition 3. If the agent sets $x_{A}^{*}(\omega)=0$ for $\omega \in\{0,1\}$ and $x_{A}^{*}(\theta)=\theta$ and overseer beliefs are consistent with this strategy then the overseer will uphold upon observing $x_{A}=\theta$. Similarly, the overseer will uphold $x_{A}=0$ since either (a) she is indifferent since reversal leads to $x=0$ with a shock $\varepsilon(0)$ or (b) she is better off upholding because the agency chose $e=1$, which leads to $x=0$ with $\varepsilon(1)$. Finally, to complete the sequential rationality of the overseer's strategy set the overseer's beliefs following $x_{A}=1$ to $\operatorname{Pr}\left[\omega=1 \mid x_{A}=1\right]=1$, which leads the overseer to reverse given $\beta$. Verifying the agency's stated strategy as a best response only requires consideration of $x_{A}(1)=0$ since $x_{A}^{*}(\omega)=\omega$ when $\omega \in\{0, \theta\}$. Setting $x_{A}(1)=1$ induces $r(1, e)=1$ which leads to a net payoff of:

$$
\begin{aligned}
\Delta E U_{A}\left(x_{A}(1)=1\right) & =E U_{A}\left(x_{A}(1)=1 \mid r(1, e)=1\right)-E U_{A}\left(x_{A}(1)=0 \mid r(0, e)=0\right) \\
& =-1-V_{\varepsilon}(0)-\pi+1+V_{\varepsilon}(e), \\
& =V_{\varepsilon}(e)-V_{\varepsilon}(0)-\pi,
\end{aligned}
$$

which is always negative since $\pi>0$ and $V_{\varepsilon}(e) \leq V_{\varepsilon}(0)$. Thus, the agency never benefits from deviating to $x_{A}(1)=1$ from $x_{A}^{*}(1)=0$. Now consider the analogous payoff for $x_{A}(1)=\theta$, which would induce $r(\theta, e)=0$ :

$$
\begin{aligned}
\Delta E U_{A}\left(x_{A}(1)=\theta\right) & =E U_{A}\left(x_{A}(1)=\theta \mid r(\theta, e)=0\right)-E U_{A}\left(x_{A}(1)=0 \mid r(0, e)=0\right), \\
& =-(1-\theta)^{2}-V_{\varepsilon}(e)+1+V_{\varepsilon}(e), \\
& =1-(1-\theta)^{2}
\end{aligned}
$$

which is always negative given that $\theta>2$ (and therefore $(1-\theta)^{2}>1$ ). Thus, the agency does not benefit from deviating from $x_{A}^{*}(1)=0$ to $x_{A}(1)=\theta$. Taken together, the players are best responding and therefore these strategies, along with appropriate and consistent beliefs of the overseer, form a PBE. 


\section{B.3.2 Obfuscation through exaggeration}

Proposition 4. When $\theta<2$, preference disagreement is such that $\beta \in\left(\beta_{\text {align }}^{S}(e), \beta_{\text {ext }}^{S}(e)\right)$, and $\omega=\theta$ is sufficiently likely relative to $\omega=1$ :

$$
\frac{p_{1}}{p_{1}+p_{\theta}} \leq \frac{\theta(\theta-2 \beta)+V_{\varepsilon}(0)-V_{\varepsilon}(e)}{2 \theta(\theta-1)},
$$

there is a semi-pooling equilibrium in which the agency obfuscates through exaggeration by setting $x(0)=0$ and $x(\omega)=\theta$ for $\omega \in\{1, \theta\}$ and the overseer upholds $x_{A} \in\{0, \theta\}$ and reverses $x_{A}=1$.

Proof of Proposition 4. Consider the agency's semi-pooling strategy in which:

$$
x_{A}^{*}(\omega)= \begin{cases}\theta & \text { if } \omega \in\{1, \theta\} \\ 0 & \text { if } \omega=0 .\end{cases}
$$

Given correct beliefs $\operatorname{Pr}\left[\omega=0 \mid x_{A}=0\right]=1$ the overseer has no reason to reverse $x_{A}=0$. Moreover, set $\operatorname{Pr}\left[\omega=1 \mid x_{A}=1\right]=1$ so that the overseer reverses following $x_{A}=1$ given $\beta$. Finally, consider $r\left(x_{A}, e\right)$ when $x_{A}=\theta$. Let $b_{R}(1 \mid \theta)=\operatorname{Pr}\left[\omega=1 \mid x_{A}=\theta\right]=\frac{p_{1}}{p_{1}+p_{\theta}}$ and $b_{R}(\theta \mid \theta)=\operatorname{Pr}\left[\omega=\theta \mid x_{A}=\right.$ $\theta]=\frac{p_{\theta}}{p_{1}+p_{\theta}}$ be the overseer's (correct) beliefs (consistent with $x_{A}^{*}(\omega)$ ) following $x_{A}=\theta$ that $\omega=1$ and $\omega=\theta$, respectively. After observing $x_{A}=\theta$, given $x_{A}^{*}(\omega)$, the overseer upholds if and only if:

$$
\begin{aligned}
-b_{R}(1 \mid \theta)(1-\beta-\theta)^{2}-b_{R}(\theta \mid \theta) \beta^{2}-V_{\varepsilon}(e) & \geq-b_{R}(1 \mid \theta)(1-\beta)^{2}-b_{R}(\theta \mid \theta)(\theta-\beta)^{2}-V_{\varepsilon}(0), \\
-\left(\frac{p_{1}}{p_{1}+p_{\theta}}(1-\beta-\theta)^{2}+\frac{p_{\theta}}{p_{1}+p_{\theta}} \beta^{2}+V_{\varepsilon}(e)\right) & \geq-\left(\frac{p_{1}}{p_{1}+p_{\theta}}(1-\beta)^{2}-\frac{p_{\theta}}{p_{1}+p_{\theta}}(\theta-\beta)^{2}+V_{\varepsilon}(0)\right), \\
\frac{p_{1}}{p_{1}+p_{\theta}} & \leq \frac{\theta^{2}-2 \beta \theta+V_{\varepsilon}(0)-V_{\varepsilon}(e)}{2 \theta(\theta-1)} .
\end{aligned}
$$

Thus, given the overseer's beliefs consistent with $x_{A}^{*}(\omega)$, the overseer's review strategy is a best response to $x_{A}^{*}(\omega)$. To verify that $x_{A}^{*}(\omega)$ is a best response to the overseer's review strategy we again need only check the case when $\omega=1$. When $\omega \in\{0, \theta\}$ the agency is matching policy to the state and being upheld so there is clearly no reason to deviate. If the agency were to truthfully set $x_{A}(1)=1$, given overseer beliefs fixed above at $\operatorname{Pr}\left[\omega=1 \mid x_{A}=1\right]=1$, the overseer will reverse the agency leading to a net negative payoff for deviation:

$$
\begin{aligned}
\Delta E U_{A}\left(x_{A}(1)=1\right) & =E U_{A}\left(x_{A}(1)=1 \mid r(1, e)=1\right)-E U_{A}\left(x_{A}^{*}(1)=\theta \mid r(\theta, e)=0\right), \\
& =-1-V_{\varepsilon}(0)-\kappa e-\pi+(1-\theta)^{2}+V_{\varepsilon}(e)-\kappa e, \\
& =(1-\theta)^{2}-1+V_{\varepsilon}(e)-V_{\varepsilon}(0)-\pi,
\end{aligned}
$$


which is always negative since (i) $(1-\theta)^{2}<1$ because $\theta<2$, (ii) $V_{\varepsilon}(e)-V_{\varepsilon}(1) \leq 0$, and (iii) $\pi>0$. Thus, the agency is strictly better off under $x_{A}^{*}(\omega)$ given $r^{*}\left(x_{A}^{*}(\omega), e\right)$ in this case. Finally, consider a deviation to $x_{A}(1)=0$, which will also be upheld, instead of $x_{A}^{*}(1)=\theta$ :

$$
\begin{aligned}
\Delta E U_{A}\left(x_{A}(1)=0\right) & =E U_{A}\left(x_{A}(1)=0 \mid r(0, e)=0\right)-E U_{A}\left(x_{A}^{*}(1)=\theta \mid r(\theta, e)=0\right), \\
& =-1-V_{\varepsilon}(e)-\kappa e+(1-\theta)^{2}+V_{\varepsilon}(e)-\kappa e, \\
& =(1-\theta)^{2}-1,
\end{aligned}
$$

which is always negative since $\theta<2$ (implying $\left.(1-\theta)^{2}<1\right)$. Thus, $x_{A}^{*}(\omega)$ is a best response to the overseer's review strategy. Taken together, these strategies, along with consistent overseer beliefs, form a PBE.

Proposition B.1. When $\theta<2$, preference disagreement is such that $\beta \in\left(\beta_{\text {align }}^{S}(e), \beta_{\text {ext }}^{s}(e)\right)$, and equation (2) does not hold:

$$
\frac{p_{1}}{p_{1}+p_{\theta}}>\frac{\theta(\theta-2 \beta)+V_{\varepsilon}(0)-V_{\varepsilon}(e)}{2 \theta(\theta-1)},
$$

there is a semi-pooling equilibrium in which the agency mixes between $x_{A}=\theta$ and $x_{A}=0$ when $\omega=1$ and chooses $x_{A}=\omega$ for $\omega \in\{0, \theta\}$ :

$$
x_{A}^{m i x}(\omega)= \begin{cases}\theta & \text { with probability } \frac{p_{\theta}\left(\theta(\theta-2 \beta)+V_{\varepsilon}(0)-V_{\varepsilon}(e)\right)}{p_{1}\left(\theta(\theta-2+2 \beta)+V_{\varepsilon}(e)-V_{\varepsilon}(0)\right)} \text { if } \omega=1 \\ 0 & \text { with probability } 1-\frac{p_{\theta}\left(\theta(\theta-2 \beta)+V_{\varepsilon}(0)-V_{\varepsilon}(e)\right)}{p_{1}\left(\theta(\theta-2+2 \beta)+V_{\varepsilon}(e)-V_{\varepsilon}(0)\right)} \text { if } \omega=1 \\ \omega & \text { if } \omega \in\{0, \theta\}\end{cases}
$$

and the overseer reverses $x_{A}$ according the following strategy:

$$
s_{R}^{*}\left(x_{A}, e\right)= \begin{cases}\text { Uphold: } 0 & \text { if } x_{A}=0, \\ \text { Reverse: } 1 & \text { if } x_{A}=1, \\ \text { Uphold: } 0 & \text { with probability } 1-\frac{\theta(\theta-2)}{\theta(\theta-2)+V_{\varepsilon}(e)-V_{\varepsilon}(0)-\pi} \text { if } x_{A}=\theta, \\ \text { Reverse: } 1 & \text { with probability } \frac{\theta(\theta-2)}{\theta(\theta-2)+V_{\varepsilon}(e)-V_{\varepsilon}(0)-\pi} \text { if } x_{A}=\theta .\end{cases}
$$

Proof of Proposition B.1. In this environment it is straightforward to show that, given the overseer's strategy $s_{R}^{*}\left(x_{A}, e\right)$, the agency's best response is $x_{A}=0$ when $\omega=0$ and, supposing that the agency is mixing between $x_{A}=0$ and $x_{A}=\theta$ when $\omega=1$, that $x_{A}=\theta$ when $\omega=\theta$ is also a best response. The overseer upholding $x_{A}=0$ is also clearly a best response since, given the preference environment, the overseer prefers both (i) the agency to set $x_{A}=0$ when $\omega=0$ and (ii) the agency to set $x_{A}=0$ when $\omega=1$. So in all instances in which $x_{A}=0$ would be observed, given $x_{A}^{m i x}(\omega)$, the agency is 
setting policy in line with overseer preferences. Note also that the preference environment implies that overturning $x_{A}=1$ is a best response. Thus, what remains to be shown is that (a) the agency is best responding when $\omega=1$ and (b) the overseer is best responding when $x_{A}=\theta$. This involves deriving when the two players are indifferent between the two actions prescribed by their respective strategies $\left(x_{A}^{m i x}(\omega)\right.$ and $\left.s_{R}^{*}\left(x_{A}, e\right)\right)$ in those settings.

First, note that the agency's payoff for setting $x_{A}(1)=1$ given $s_{R}^{*}\left(x_{A}, e\right)$ is $E U_{A}\left(x_{A}=1 \mid \omega=\right.$ $1, r(1, e)=1)=-1-V_{\varepsilon}(0)-\kappa e-\pi$ while the payoff for setting $x_{A}(1)=0$ given $s_{R}^{*}\left(x_{A}, e\right)$ is $E U_{A}\left(x_{A}=0 \mid \omega=1, r(1, e)=0\right)=-1-V_{\varepsilon}(e)-\kappa e$. Clearly $E U_{A}\left(x_{A}=0 \mid \omega=1, r(1, e)=0\right)>$ $E U_{A}\left(x_{A}=1 \mid \omega=1, r(1, e)=1\right)$ since $V_{\varepsilon}(0)-V_{\varepsilon}(e) \geq 0$ and $\pi>0$ so agency mixing when $\omega=1$ is between $x_{A}=0$ and $x_{A}=\theta$. Letting $\phi:=\operatorname{Pr}\left[x_{A}=\theta \mid \omega=1\right]$ the overseer can mix between $r(\theta, e)=0$ and $r(\theta, e)=1$ when $x_{A}=\theta$ only if:

$$
\frac{p_{1} \phi}{p_{1} \phi+p_{\theta}}=\frac{\theta(\theta-2 \beta)+V_{\varepsilon}(0)-V_{\varepsilon}(e)}{2 \theta(\theta-1)}
$$

which implies that:

$$
\phi=\frac{p_{\theta}\left(\theta(\theta-2 \beta)+V_{\varepsilon}(0)-V_{\varepsilon}(e)\right)}{p_{1}\left(\theta(\theta-2+2 \beta)+V_{\varepsilon}(e)-V_{\varepsilon}(0)\right)}
$$

The restrictions in the environment ensure that $\phi$ as defined in equation (5) is positive and less than one (i.e., $\phi \in(0,1))$.

Now, letting $\rho:=\operatorname{Pr}\left[r\left(x_{A}, e\right)=1 \mid x_{A}=\theta\right]$ denote the probability the overseer reverses following $x_{A}=\theta$ the agency's expected payoff from setting $x_{A}(1)=\theta$ is given by:

$$
E U_{A}\left(x_{A}=\theta \mid \omega=1, \rho\right)=\rho\left[-1-V_{\varepsilon}(0)-\kappa e-\pi\right]+(1-\rho)\left[-(1-\theta)^{2}-V_{\varepsilon}(e)-\kappa e\right]
$$

and the agency's analogous expected payoff from setting $x_{A}(1)=0$ (which induces $r(1, e)=0$ ) is given by:

$$
E U_{A}\left(x_{A}=0 \mid \omega=1, r(1, e)=0\right)=-1-V_{\varepsilon}(e)-\kappa e .
$$

In order to choose $\phi \in(0,1)$ it must be that:

$$
\begin{aligned}
E U_{A}\left(x_{A}=\theta \mid \omega=1, \rho\right) & =E U_{A}\left(x_{A}=0 \mid \omega=1, r(1, e)=0\right), \\
\rho & =\frac{\theta(\theta-2)}{\theta(\theta-2)+V_{\varepsilon}(e)-V_{\varepsilon}(0)-\pi} .
\end{aligned}
$$

Note that $\theta \in(\underline{\theta}, 2)$ and $\pi>0$ ensure that $\rho \in(0,1)$. So long as $r(\theta, e)=\rho$ the agent is indifferent 
between choosing $x_{A}=\theta$ and $x_{A}=0$ when $\omega=1$ and can set $x_{A}=\theta$ with probability $\phi$ and $x_{A}=0$ with probability $1-\phi$. Doing so and choosing $x_{A}=\omega$ when $\omega \in\{0, \theta\}$ with probability one, along with consistency of overseer beliefs, implies that the overseer is indifferent between $r(\theta, e)=1$ and $r(\theta, e)=0$ so that she can choose the former with probability $\rho$ and the latter with probability $1-\rho$. To complete the equilibrium, set the overseer's off-path beliefs after observing $x_{A}=1$ to $\operatorname{Pr}\left[\theta=1 \mid x_{A}=1\right]=1$.

\section{B.4 Equilibrium effort}

Lemma B.1. Define $\beta_{\text {align }}^{S}(e):=\frac{1+V_{\varepsilon}(0)-V_{\varepsilon}(e)}{2}$ and $\beta_{\text {ext }}^{S}(e):=\frac{\theta^{2}+V_{\varepsilon}(0)-V_{\varepsilon}(e)}{2 \theta}$. Note that $0<\beta_{\text {align }}^{S}(0)<$ $\beta_{\text {align }}^{S}(1)<\beta_{\text {ext }}^{S}(0)<\beta_{\text {ext }}^{S}(1)$ since $V_{\varepsilon}(0)>V_{\varepsilon}(1)$. Conditional on the overseer's bias $\beta$, which dictates the type of signaling outlined in Figure 3, the agency invests effort as follows:

1. If $\beta<\beta_{\text {align }}^{S}(0)$ then there is a truthful separating equilibrium in which the agency invests high effort if and only if $V_{\varepsilon}(0)-V_{\varepsilon}(1) \geq \kappa$.

2. If $\beta_{\text {align }}^{S}(0)<\beta<\beta_{\text {align }}^{S}(1)$ then there is a truthful separating equilibrium following high effort and a semi-pooling obfuscation equilibrium after low effort, which depends further on $\theta$.

(a) When $\theta<2$ the agency invests high effort and obfuscates through exaggeration if and only if $p_{1}(1-\theta)^{2}+V_{\varepsilon}(0)-V_{\varepsilon}(1) \geq \kappa$.

(b) When $\theta>2$ the agency invests high effort and obfuscates to appease if and only if $p_{1}+V_{\varepsilon}(0)-V_{\varepsilon}(1) \geq \kappa$.

3. If $\beta_{\text {align }}^{S}(1)<\beta<\beta_{\text {ext }}^{S}(0)$ then there is a semi-pooling obfuscation equilibrium following both high and low effort, obfuscation through exaggeration or obfuscation to appease depending on $\theta$, and the agency invests high effort if and only if $V_{\varepsilon}(0)-V_{\varepsilon}(1) \geq \kappa$.

4. If $\beta_{\text {ext }}^{S}(0)<\beta<\beta_{\text {ext }}^{S}(1)$ then there is a semi-pooling obfuscation equilibrium following high effort, which depends further on $\theta$, and a pooling to placate equilibrium following low effort.

(a) When $\theta<2$ the agency invests high effort and obfuscates through exaggeration if and only if $p_{1}\left(1-(1-\theta)^{2}\right)+p_{\theta} \theta^{2}+V_{\varepsilon}(0)-V_{\varepsilon}(1) \geq \kappa$.

(b) When $\theta>2$ the agency invests high effort and obfuscates to appease if and only if $p_{\theta} \theta^{2}+V_{\varepsilon}(0)-V_{\varepsilon}(1) \geq \kappa$.

5. If $\beta>\beta_{\text {ext }}^{S}(1)$ then there is a pooling to placate equilibrium following both high and low effort. The agency invests high effort if and only if $V_{\varepsilon}(0)-V_{\varepsilon}(1) \geq \kappa$.

Proof of Lemma B.1. Each case requires deriving the agency's incentive compatibility condition for high effort given the type of policymaking strategy (and review strategy) that will follow. 
Case 1: $\beta<\beta_{\text {align }}^{S}(0)$. In this case there is a truthful separating equilibrium following both low and high effort. Thus, $r^{*}\left(x_{A}(\omega)=\omega, e\right)=0$ for all $e$ and the agency's incentive compatibility condition for high effort is given by:

$$
\begin{aligned}
E U_{A}\left(e=1 \mid \beta \leq \beta_{\text {align }}^{S}(0)\right) & \geq E U_{A}\left(e=0 \mid \beta \leq \beta_{\text {align }}^{S}(0)\right), \\
-p_{0} V_{\varepsilon}(1)-p_{1} V_{\varepsilon}(1)-p_{\theta} V_{\varepsilon}(1)-\kappa & \geq-p_{0} V_{\varepsilon}(0)-p_{1} V_{\varepsilon}(0)-p_{\theta}, \\
-V_{\varepsilon}(1)-\kappa & \geq-V_{\varepsilon}(0), \\
V_{\varepsilon}(0)-V_{\varepsilon}(1) & \geq \kappa,
\end{aligned}
$$

as stated in the result.

Case 2: $\beta_{\text {align }}^{S}(0)<\beta \leq \beta_{\text {align }}^{S}(1)$. In this case there is a truthful separating equilibrium after $e=1$ and a semi-pooling obfuscation equilibrium after $e=0$. If $\theta>2$ then the agency obfuscates to appease and if $\theta<2$ then the agency obfuscates through exaggeration. Consider first the case in which $\theta>2$ :

$$
\begin{aligned}
E U_{A}\left(e=1 \mid \beta_{\text {align }}^{S}(0)<\beta \leq \beta_{\text {align }}^{S}(1), \theta>2\right) & \geq E U_{A}\left(e=0 \mid \beta_{\text {align }}^{S}(0)<\beta \leq \beta_{\text {align }}^{S}(1), \theta>2\right), \\
-V_{\varepsilon}(1)-\kappa & \geq-p_{0} V_{\varepsilon}(0)-p_{1}\left(1+V_{\varepsilon}(0)\right)-p_{\theta} V_{\varepsilon}(0), \\
-V_{\varepsilon}(1)-\kappa & \geq-p_{1}-V_{\varepsilon}(0), \\
p_{1}+V_{\varepsilon}(0)-V_{\varepsilon}(1) & \geq \kappa,
\end{aligned}
$$

as stated in the result. Now suppose that $\theta<2$. The associated incentive compatibility condition for high effort is:

$$
\begin{gathered}
E U_{A}\left(e=1 \mid \beta_{\text {align }}^{S}(0)<\beta \leq \beta_{\text {align }}^{S}(1), \theta<2\right) \geq E U_{A}\left(e=0 \mid \beta_{\text {align }}^{S}(0)<\beta \leq \beta_{\text {align }}^{S}(1), \theta<2\right), \\
-V_{\varepsilon}(1)-\kappa \geq-p_{0} V_{\varepsilon}(0)-p_{1}\left((1-\theta)^{2}+V_{\varepsilon}(0)\right)-p_{\theta} V_{\varepsilon}(0), \\
-V_{\varepsilon}(1)-\kappa \geq-p_{1}(1-\theta)^{2}-V_{\varepsilon}(0), \\
p_{1}(1-\theta)^{2}+V_{\varepsilon}(0)-V_{\varepsilon}(1) \geq \kappa,
\end{gathered}
$$

as stated in the result.

Case 3: $\beta_{\text {align }}^{S}(1)<\beta<\beta_{\text {ext }}^{S}(0)$. In this case the agency semi-pools following both $e=0$ and $e=1$. Since the substance of policy will be the same regardless of $e$ it follows that the incentive compatibility condition for high effort is simply $V_{\varepsilon}(0)-V_{\varepsilon}(1) \geq \kappa$ as in the first case in which there is a truthful separating equilibrium regardless of $e$. So long as the spatial location of $x$ does not change based on $e$ the only relevant consideration is whether the precision improvement from high effort, $V_{\varepsilon}(0)-V_{\varepsilon}(1)$, outweighs the cost of that improvement, $\kappa$. 
Case 4: $\beta_{\text {ext }}^{S}(0)<\beta<\beta_{\text {ext }}^{S}(1)$. In this case the agency obfuscates through semi-pooling after $e=1$ and pools to placate after $e=0$. Accordingly, there are again two cases depending on $\theta$. Suppose first that $\theta>2$. The agency invests high effort if and only if:

$$
\begin{gathered}
E U_{A}\left(e=1 \mid \beta_{\text {align }}^{S}(1)<\beta<\beta_{\text {ext }}^{S}(0), \theta>2\right) \geq E U_{A}\left(e=0 \mid \beta_{\text {align }}^{S}(1)<\beta<\beta_{\text {ext }}^{S}(0), \theta>2\right), \\
-p_{1}-V_{\varepsilon}(1)-\kappa \geq-p_{1}-p_{\theta} \theta^{2}-V_{\varepsilon}(0), \\
p_{\theta} \theta^{2}+V_{\varepsilon}(0)-V_{\varepsilon}(1) \geq \kappa,
\end{gathered}
$$

as stated in the result. The analogous condition when $\theta<2$ is given by:

$$
\begin{gathered}
E U_{A}\left(e=1 \mid \beta_{\text {align }}^{S}(1)<\beta<\beta_{\text {ext }}^{S}(0), \theta<2\right) \geq E U_{A}\left(e=0 \mid \beta_{\text {align }}^{S}(1)<\beta<\beta_{\text {ext }}^{S}(0), \theta<2\right), \\
-p_{1}(1-\theta)^{2}-V_{\varepsilon}(1)-\kappa \geq-p_{1}-p_{\theta} \theta^{2}-V_{\varepsilon}(0), \\
p_{1}-p_{1}(1-\theta)^{2}+p_{\theta} \theta^{2}+V_{\varepsilon}(0)-V_{\varepsilon}(1) \geq \kappa,
\end{gathered}
$$

as stated in the result.

Case 5: $\beta>\beta_{\text {ext }}^{S}(1)$. In this case the agency pools to placate by setting $x_{A}=0$ regardless of $\omega$ and $e$. Similar to cases 1 and 3 above, this implies that the relevant incentive compatibility condition for high effort is $V_{\varepsilon}(0)-V_{\varepsilon}(1) \geq \kappa$ since the spatial location of policy is zero regardless of $e$. Thus, the only relevant consideration is whether the induced precision improvements from high effort are sufficient to outweigh the cost for that improvement.

Corollary B.1. The agency's discretion to match policy to the state is higher when the agency invests high effort.

Proof of Corollary B.1. This follows from comparison of Case 2 to Case 1 and Case 4 to Case 3 in the proof of Lemma B.1. Specifically, note that, regardless of $\theta$, in both cases the agency is able to set $x_{A}=\omega$ for more instances of $\omega$. In the first comparison (case 2 and case 1 ), the agency is able to match $x_{A}(\omega)=\omega$ for all $\omega$ after high effort whereas it can only match $x_{A}(\omega)=\omega$ for $\omega \in\{0, \theta\}$ after low effort. This implies that the agency is able to match policy to the state strictly more for a higher level of preference disagreement than following low effort. In the second comparison (case 4 to case 3$)$, the agency is able to match $x_{A}(\omega)=\omega$ for $\omega \in\{0, \theta\}$ after high effort and only matches $x_{A}(\omega)=\omega$ for $\omega=0$ after low effort. Again, this implies that the agency is better able to match policy to the state for higher levels of preference disagreement following high effort. Thus, overall, high effort allows the agency to better match policy to the state for higher levels of bias. 


\section{Reviewing procedure vs. judging substance}

Proposition 5. Suppose $\beta \in\left(\beta^{P}(0), \beta^{P}(1)\right), \beta \in\left(\beta_{\text {align }}^{S}(1), \beta_{\text {ext }}^{S}(0)\right)$, and equation (3) is satisfied so that procedural review is conditionally-deferential and substantive review always leads to a semipooling obfuscation equilibrium. If $\theta>2$ then the agency obfuscates to appease and overseer welfare is higher under procedural review if and only if effort costs are intermediate, $\kappa^{S}<\kappa<\kappa^{P}$, and $V_{\varepsilon}(0)-V_{\varepsilon}(1)>p_{1}(2 \beta-1)$. If $\theta<2$ then the agency obfuscates through exaggeration and overseer welfare is always higher under procedural review.

Proof of Proposition 5. Consider an environment where $\beta \in\left(\beta_{0}^{P}, \beta_{1}^{P}\right)$ and $\beta \in\left(\beta_{\text {align }}^{S}(1), \beta_{\text {ext }}^{S}(0)\right)$ so that under procedural review we are in a conditional-deference environment and, from Lemma A.3, the agency exerts high effort if and only if $p_{1}+p_{\theta} \theta^{2}+V_{\varepsilon}(0)-V_{\varepsilon}(1)+\pi \geq \kappa$, and under substantive review we are in a semi-pooling obfuscation equilibrium. If $\theta<2$ then the agency obfuscates through exaggeration (i.e., $x_{A}^{*}(0)=0$ and $x_{A}^{*}(\omega)=\theta$ for $\omega \in\{1, \theta\}$ ) and if $\theta>2$ then the agency obfuscates to appease (i.e., $x_{A}^{*}(\omega)=0$ for $\omega \in\{0,1\}$ and $x_{A}^{*}(\theta)=\theta$ ). In both cases the agency exerts high effort if and only if $V_{\varepsilon}(0)-V_{\varepsilon}(1) \geq \kappa$ (from Lemma B.1). Denote the upper bounds on $\kappa$ to support high effort under procedural review and substantive review, respectively, as $\kappa^{P}:=p_{1}+p_{\theta} \theta^{2}+V_{\varepsilon}(0)-V_{\varepsilon}(1)+\pi$ and $\kappa^{S}:=V_{\varepsilon}(0)-V_{\varepsilon}(1)$. Note that $\kappa^{P}>\kappa^{S}$ so that high effort is more likely in the sense of set inclusion under procedural review. Thus there are three cases of effort across regimes: (1) if $\kappa>\kappa^{P}$ then $e=0$ under both procedural and substantive review; (2) if $\kappa \in\left(\kappa^{S}, \kappa^{P}\right]$ then $e=0$ under substantive review and $e=1$ under procedural review; (3) if $\kappa \leq \kappa^{S}$ then $e=1$ under both procedural and substantive review.

With these possibilities in mind we can compute the overseer's ex ante welfare for each:

$$
\begin{aligned}
W^{P}(e=1 \mid \beta \text { moderate }) & =-p_{0}\left(\beta^{2}+V_{\varepsilon}(1)\right)-p_{1}\left(\beta^{2}+V_{\varepsilon}(1)\right)-p_{\theta}\left(\beta^{2}+V_{\varepsilon}(1)\right), \\
& =-\beta^{2}-V_{\varepsilon}(1), \\
W^{P}(e=0 \mid \beta \text { moderate }) & =-p_{0}\left(\beta^{2}+V_{\varepsilon}(0)\right)-p_{1}\left((1-\beta)^{2}+V_{\varepsilon}(0)\right)-p_{\theta}\left((\theta-\beta)^{2}+V_{\varepsilon}(0)\right), \\
& =-p_{0} \beta^{2}-p_{1}(1-\beta)^{2}-p_{\theta}(\theta-\beta)^{2}-V_{\varepsilon}(0), \\
W^{S}(e \mid \beta \text { moderate, } \theta>2) & =-p_{0} \beta^{2}-p_{1}(1-\beta)^{2}-p_{\theta} \beta^{2}-V_{\varepsilon}(e), \\
W^{S}(e \mid \beta \text { moderate }, \theta<2) & =-p_{0} \beta^{2}-p_{1}(1-\beta-\theta)^{2}-p_{\theta} \beta^{2}-V_{\varepsilon}(e) .
\end{aligned}
$$

Obfuscation to appease. Consider the case in which $\theta>2$ so the agency obfuscates to appease under substantive review. We can evaluate each case that depends on $\kappa$. First, let $\kappa>\kappa^{P}>\kappa^{S}$ so 
that $e=0$ regardless of review type:

$$
\begin{aligned}
W^{P}(e=0 \mid \beta \text { moderate, } \theta>2) & <W^{S}(e=0 \mid \beta \text { moderate, } \theta>2), \\
-p_{0} \beta^{2}-p_{1}(1-\beta)^{2}-p_{\theta}(\theta-\beta)^{2}-V_{\varepsilon}(0) & <-p_{0} \beta^{2}-p_{1}(1-\beta)^{2}-p_{\theta} \beta^{2}-V_{\varepsilon}(0), \\
p_{\theta} \beta^{2} & <p_{\theta}(\theta-\beta)^{2}, \\
0 & <p_{\theta} \theta(\theta-2 \beta),
\end{aligned}
$$

which is always satisfied for $\theta>2$ and the range of $\beta$ in this environment. Thus, the overseer is better off under substantive review.

Now consider the case in which $\kappa \in\left(\kappa^{S}, \kappa^{P}\right]$ so that $e=0$ under substantive review and $e=1$ under procedural review:

$$
\begin{gathered}
W^{P}(e=1 \mid \beta \text { moderate, } \theta>2)<W^{S}(e=0 \mid \beta \text { moderate, } \theta>2), \\
-\beta^{2}-V_{\varepsilon}(1)<-p_{0} \beta^{2}-p_{1}(1-\beta)^{2}-p_{\theta} \beta^{2}-V_{\varepsilon}(0), \\
V_{\varepsilon}(0)-V_{\varepsilon}(1)<p_{1}(2 \beta-1),
\end{gathered}
$$

which yields the condition for substantive review to be preferred to procedural review. Thus, $W^{P}>$ $W^{S}$ when the precision improvement from high effort outweighs the overseer's ability to induce $x_{A}=0$ when $\omega=1: V_{\varepsilon}(0)-V_{\varepsilon}(1)>p_{1}(2 \beta-1)$. Otherwise, substantive review produces higher welfare for the overseer.

Finally, suppose that $\kappa<\kappa^{S}<\kappa^{P}$ so that $e=1$ under both procedural and substantive review:

$$
\begin{aligned}
W^{P}(e=1 \mid \beta \text { moderate, } \theta>2) & <W^{S}(e=1 \mid \beta \text { moderate, } \theta>2), \\
-\beta^{2}-V_{\varepsilon}(1) & <-p_{0} \beta^{2}-p_{1}(1-\beta)^{2}-p_{\theta} \beta^{2}-V_{\varepsilon}(1), \\
0 & <p_{1}(2 \beta-1)
\end{aligned}
$$

which is always satisfied since $\beta>\frac{1}{2}$ in this setting. Thus, the overseer always benefits from substantive review in this setting. Taken together this implies that when $\theta>2$ the only time the overseer's welfare is higher under procedural review is when (a) $\kappa \in\left(\kappa^{S}, \kappa^{P}\right]$ and (b) $V_{\varepsilon}(0)-V_{\varepsilon}(1)>$ $p_{1}(2 \beta-1)$.

Obfuscation through exaggeration. Let $\theta<2$ so the agency obfuscates through exaggeration under substantive review. Suppose that $\kappa>\kappa^{P}>\kappa^{S}$ so that $e=0$ under both procedural and substantive 
review:

$$
\begin{aligned}
W^{P}(e=0 \mid \beta \text { moderate, } \theta<2) & >W^{S}(e=0 \mid \beta \text { moderate }, \theta<2), \\
-p_{0} \beta^{2}-p_{1}(1-\beta)^{2}-p_{\theta}(\theta-\beta)^{2}-V_{\varepsilon}(0) & >-p_{0} \beta^{2}-p_{1}(1-\beta-\theta)^{2}-p_{\theta} \beta^{2}-V_{\varepsilon}(0), \\
0 & >p_{1}(1-\beta)^{2}-p_{1}(1-\beta-\theta)^{2}+p_{\theta}(\theta-\beta)^{2}-p_{\theta} \beta^{2} .
\end{aligned}
$$

This inequality is always satisfied in this setting, which implies that the overseer always benefits from procedural review in this case.

Now suppose that $\kappa \in\left(\kappa^{S}, \kappa^{P}\right]$ so $e=0$ under substantive review and $e=1$ under procedural review:

$$
\begin{aligned}
W^{P}(e=1 \mid \beta \text { moderate }, \theta<2) & >W^{S}(e=0 \mid \beta \text { moderate, } \theta<2), \\
-\beta^{2}-V_{\varepsilon}(1) & >-p_{0} \beta^{2}-p_{1}(1-\beta-\theta)^{2}-p_{\theta} \beta^{2}-V_{\varepsilon}(0), \\
V_{\varepsilon}(0)-V_{\varepsilon}(1)+p_{1}+2 p_{1} \beta \theta+p_{1} \theta^{2}-2 p_{1} \beta-2 p_{1} \theta & >0, \\
V_{\varepsilon}(0)-V_{\varepsilon}(1)+p_{1}(1+\theta(2 \beta+\theta)-2(\beta+\theta)) & >0 .
\end{aligned}
$$

Again, this inequality is always satisfied in this setting, which implies that the overseer once again benefits from procedural review.

Finally, suppose that $\kappa<\kappa^{S}<\kappa^{P}$ so that $e=1$ under both procedural and substantive review:

$$
\begin{aligned}
W^{P}(e=1 \mid \beta \text { moderate, } \theta<2) & >W^{S}(e=1 \mid \beta \text { moderate, } \theta<2), \\
-\beta^{2}-V_{\varepsilon}(1) & >-p_{0} \beta^{2}-p_{1}(1-\beta-\theta)^{2}-p_{\theta} \beta^{2}-V_{\varepsilon}(1), \\
p_{1}(1+\theta(2 \beta+\theta)-2(\beta+\theta)) & >0 .
\end{aligned}
$$

Once again this inequality is always satisfied and the overseer benefits from procedural review. Taken together this implies that when $\theta<2$ the overseer's welfare is always higher under pure procedural review. 